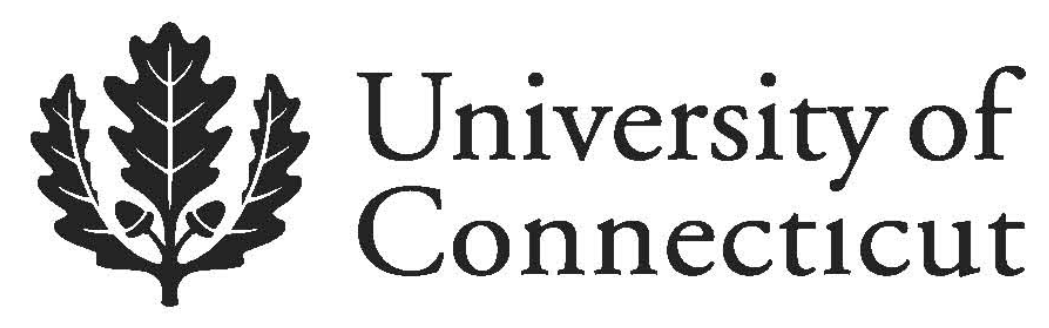

Department of Economics Working Paper Series

Education Policies and Practices: What Have We Learnt and the Road Ahead for Bihar

Priya Ranjan

University of California-Irvine

Nishith Prakash

University of Connecticut

Working Paper 2012-19

May 2012

365 Fairfield Way, Unit 1063

Storrs, CT 06269-1063

Phone: (860) 486-3022

Fax: (860) 486-4463

http://www.econ.uconn.edu/

This working paper is indexed on RePEc, http://repec.org 
May 3, 2012

\title{
Education Policies and Practices: What Have We Learnt and the Road Ahead for Bihar
}

\author{
Priya Ranjan \\ University of California, Irvine \\ Nishith Prakash \\ University of Connecticut, IZA \& CReAM
}

\begin{abstract}
This paper assesses the status of education, both quantity and quality, in Bihar in both absolute terms and relative to other states in India. It then performs a regression exercise using a panel data of Indian states to identify the correlates of educational outcomes. It also surveys the broader literature on education policies which provides a perspective on the current policies in the field of education in Bihar. Finally, it makes a case for several policy initiatives that should be accorded priority by the policymakers in Bihar.
\end{abstract}

JEL Codes: I2, J31, O15, O22.

Keywords: Education, Enrollment, Out-of-School, Bihar, India.

Contact information: Priya Ranjan, Department of Economics, University of California, Irvine, CA, 92697-5100, U.S.A (e-mail: pranjan@uci.edu).

Nishith Prakash, Department of Economics and Human Rights Institute, University of Connecticut, Storrs, CT 06269-1063, U.S.A (email: nishith.prakash@uconn.edu).

This paper was written under the aegis of International Growth Centre, U.K. We are grateful to International Growth Center at London School of Economics for funding this research proposal. We are grateful to Aimee Chin, Maitreesh Ghatak, Anjan Mukherji, officials at Ministry of Human Resources and Development, the participants at IGC Growth Week at London School of Economics and Political Science, and IGC Bihar Growth Conference in Patna, Bihar for helpful comments and suggestions. We would also like to thank Ian Michael Salas for providing excellent research assistance. We are responsible for any errors that may remain. 


\section{Introduction}

Educational attainment of a society is an important determinant of its level of economic development. If a poor state like Bihar wants to become rich, it must ensure that its children are well educated. The aim of this paper is to assess the status of education in Bihar, identify the correlates of educational outcomes, and analyze the education policy initiatives of the government of Bihar. ${ }^{1}$ It also surveys the broader literature on education policies which provides a perspective on the current policies in Bihar and allows us to make some informed policy recommendations.

We first look at the status of education (both quality and quantity) in Bihar, mainly at the primary and upper primary levels because of data availability issues, both in absolute terms and in relation to other states in India. We find that the enrolment rate at the primary level in Bihar has been increasing over time and is higher than the median of the 20 large states starting in 2006-07. The enrolment rate at the upper primary level is very low in absolute terms and right at the bottom of the 20 major states in India. An alternative way to look at enrolment is to see what percentage of school age children are not attending school. Again, Bihar has a higher percentage of children not attending school than the median state in India, however, the percentage has been declining over time. Consistent with the enrolment numbers, the out of school rate is higher among older children.

Looking at the quality dimension of education, we find that Bihar is right around the median in both "Reading attainment" and "Math attainment". Therefore, the performance is satisfactory in relative terms, however, there is a lot of scope for improvement in raising the quality of education. To cite a couple of stark statistics: $30 \%$ of students in class VI cannot read a paragraph taken from a class II textbook; $50 \%$ of class $\mathrm{V}$ students cannot solve a simple division problem.

\footnotetext{
${ }^{1}$ Bihar is the third largest state in India in terms of population with a population exceeding 100 million according to the 2011 census.
} 
Next, we look at the correlates of educational outcomes using state level data from India. We find that Bihar has the highest pupil-teacher ratio as well as the student-classroom ratio among Indian states. In 2009-10, which is the last year for which we had data, Bihar had a student-teacher ratio of 53, while the median was 26. Among other notable schooling infrastructure measure, the percentage of schools with separate girls' toilet is well below the median in Bihar. Also, more than $10 \%$ of primary schools in Bihar do not have drinking water facility.

Looking at the bivariate relationship between schooling inputs and educational outcomes we find expected results. For example, higher pupil-teacher ratio or higher student-classroom ratio is negatively associated with Reading and Math attainment and positively associated with out of school rate. Similarly, the availability of drinking water, girls' toilet, or good quality classrooms is associated with better learning outcomes and lower out of school rates.

In our regression exercise relating schooling inputs to educational outcomes using state level data from India we find that pupil-teacher is negatively associated with learning as reflected in performance on reading and math, while the availability of drinking water facility is positively associated with learning. As far as the impact on enrolment is concerned, the availability of drinking water facility and well-maintained classrooms are significantly associated with higher enrolment. As well, states which have increased the percentage of schools with separate girls' toilet have improved the enrolment of both boy and girls.

The next part of the paper is a survey of the literature on the effectiveness of education policies adopted in different parts of the world to improve both the quantity and quality of education. One policy that is extremely cost-effective in improving educational outcomes is the school based deworming program. It is heartening to note that taking this result seriously, the government of Bihar launched a massive deworming program in the early 2011, which by some estimates treated 17 million children. The government intends to do a follow up in 2012 .

The extensive survey of Glewwe et al. (2011) finds an adequately-equipped and well- 
functioning school, which means one with quality roofs, walls or floors, with usable desks, tables and chairs, and with a school library, appears to have a clear positive impact on test scores. Well maintained classrooms were found to be significant in explaining enrolment in our regression exercise as well. Also, Chaudhury et al. (2006) find schooling infrastructure to be a key determinant of teacher absence. Therefore, improving schooling infrastructure in general and classrooms in particular should be a policy imperative.

Two policy initiatives that we emphasize most in our discussions are the provision of drinking water facilities and separate girls' toilet in all schools in the state. We provide some back of the envelope calculations for the cost of providing these schooling inputs and come up with numbers that are not large by any means.

Our survey of the literature suggests that the perceived returns to schooling are much less than the market returns resulting in underinvestment in education in many developing countries. A policy implication is to reduce the gap between the perceived returns and the market returns through information campaigns. Experimental studies suggest that these information campaigns are extremely cost effective in increasing school enrolment. Since Bihar does not have a program of this kind in place, we would make a strong recommendation for launching a systemic program of information campaign regarding the returns to education.

Most studies on the link between incentive pay and educational outcomes find the effects to be positive. An essential prerequisite to the implementation of any kind of incentive pay scheme is to set up a data system for monitoring the performance of schools and teachers. Such a data system is essential in linking student performance to teacher effectiveness. We provide some back of the envelope calculations for the cost of developing such a data system. Developing such a data system will be a fruitful endeavor even if the government didn't want to implement an incentive pay scheme. It will allow the administrators to monitor the performance of schools and take remedial actions in weakly performing schools. Again, we provide some back of the envelope calculations for developing such a data system.

The rest of the paper is organized as follows. In section 2 we look at the status of 
education in Bihar relative to other states in India and provide a quantitative exercise on the correlates of educational outcomes. In section 3 we provide a survey of the literature on educational policy interventions. Section 4 discusses the policy initiatives undertaken by the government in the context of our broader survey framework and makes some policy recommendations. Section 5 provides some concluding remarks.

\section{Status of Education in Bihar}

\subsection{Quantity of Education}

We use two measures of quantity of education. First, out of school rate-percentage of school-age population not attending school (from ASER) ${ }^{2}$. Second, net enrolment ratiopercentage attending school in appropriate age group among school-age population (from DISE $)^{3}$.

Figure 1, drawn using ASER data, shows that the out of school rate among primary school age children (age 6-14) has been declining over time. It was close to $15 \%$ in 2005 but has fallen to below $5 \%$ by 2010 . While Bihar was the worst performing state by this measure in 2005, it has converged to the median by 2010 .

Figure 2 looks at the net enrolment ratio at the primary level using data from DISE. The net enrolment ratio at primary level has been increasing over time and in the last year for which DISE data for Bihar are available, it increased from below $70 \%$ in 2003-04 to almost $100 \%$ in 2006-07. This suggests that the recent enrolment drives launched by the government of Bihar has been successful in increasing the enrolment rate at the primary level.

The picture changes dramatically when we look at the upper primary level. As can be clearly seen from Figure 3, even though Bihar has made some progress in increasing enrolment at the upper primarily level, the enrolment remains abysmally low both in absolute

\footnotetext{
${ }^{2}$ Assessment Survey Evaluation Research, India.

${ }^{3}$ District Information System for Education, India.
} 
and relative terms. In relative terms, while Bihar was at the bottom in 2003-04 with an enrolment ratio of less than $20 \%$ it has increased to $48 \%$ in $2009-10$, but is still well below the median which stands at close to $60 \%$. Therefore, the enrolment drive at primary level has not been sustained for higher grades. Having looked at the quantity of education, we turn our attention to the quality dimension.

\subsection{Quality of Education}

We use two measures to look at the quality of education in Bihar. The first one has to do with the Reading attainment and looks at the percentage of children who can read a long paragraph/story from a grade 2 level textbook in their vernacular language. The second measure assesses the Math attainment of children based on the percentage of children who can solve a 3-digit by 1-digit division problem correctly. Both these measures are from ASER and are available for several years.

From Figure 4 it is clear that Bihar's performance on reading is very close to the median of 20 states. However, in absolute terms the performance is highly unsatisfactory. To cite one representative number, $30 \%$ of students in class VI cannot read a paragraph taken from a class II textbook.

Figure 5 plots data on Math attainment of children taken from ASER. Again, Bihar does reasonably well in relative terms. The Math attainment of students in Bihar is consistently at or above the median of 20 states, but the gap with the best performing state in India is substantial. However, in absolute terms, there is a vast scope for improvement. To cite one stark number: $50 \%$ of class $\mathrm{V}$ students cannot solve a simple division problem.

Having looked at the status of education in Bihar, we move to a discussion of the proximate determinants of educational outcomes in terms of various schooling inputs. 


\subsection{Correlates of Educational Outcomes}

We look at the following five schooling input measures available from DISE: Pupil-teacher ratio; Student-classroom ratio; percentage of schools with toilet for girls; percentage of schools with drinking water facility; percentage of classrooms in good condition.

Figure 6 plots the pupil-teacher ratio for primary schools in different states in India. It is clear from the figure that the pupil-teacher ratio in primary schools in Bihar is the highest among the 20 states that we look at. Even though the ratio has been declining over time, it remains the highest in the country at 53 in 2009-10 against a median of 26 .

The story for the student-classroom ratio is similar to that for pupil-teacher ratio. As shown in Figure 7, Bihar, once again is the worst performer with a very high student to classroom ratio, exceeding 80 in all years. There is a huge gap between Bihar and the median for Indian states.

Next, we look at some measures of schooling infrastructure. Figure 8 shows that Bihar has been making a steady progress in equipping schools with drinking water facilities and is closing in on the goal of drinking water facilities in all primary schools. From being below the median at the beginning of our data period, Bihar has moved beyond the median and has narrowed the gap with the best performing state in India. However, in the last year of the sample, roughly $10 \%$ of the primary schools were without drinking water facilities, which is unacceptable.

The PROBE report had found the availability of a separate girls' toilet to be an important determinant of female schooling. Figure 9 shows that Bihar has a long way to go in terms of equipping schools with separate girls' toilet. In the last year of our data only $20 \%$ of schools had separate girls' toilet which is low both in absolute and relative terms. This is a cause for concern not only because of its consequences for female enrolment and attendance but also for female teacher attendance. Bihar has been focusing on hiring female teachers for primary schools, and a lack of separate toilet can be a significant contributor to teacher absenteeism. 
Our final measure of schooling input is the proportion of classrooms in good condition. As Figure 10 shows, the proportion of classrooms in good conditions was just about $60 \%$ in the last year for which data are available. This again, is below the median and the gap between Bihar and the best performing state in India is to the order of 20 percentage points.

It is worth pointing out that when we look at the schooling inputs at the upper primary levels, we get a qualitatively similar picture. To conserve space, we do not put these figures in the paper.

Having good schooling infrastructure has been found to be a significant determinant of teacher attendance in the cross-country study of Chaudhury et al. (2006). Therefore, improving schooling infrastructure should be a policy imperative of the government of Bihar. The first aim should be to close the gap with the median state on measures where Bihar is below the median and subsequently the aim should be to close the gap with the best performing state in India.

\subsection{Cross-State Regression Analysis}

Having looked at various measures of schooling attainment and inputs, we provide some cross-state correlation analysis between the two. We first look at the simple correlation between our outcome measures and input measures provided in Table 1.

We see that all input measures (D)-(I) have intuitive bivariate associations with reading and math attainment. First, both the pupil-teacher ratio (D) and the student-classroom ratio (E) are negatively related to learning attainment (more crowded school settings are associated with lower learning attainment). All the school infrastructure variables (F)-(I), where higher numbers denote having more adequate school infrastructure, are positively related to learning attainment (better-provisioned school settings are associated with higher learning attainment).

For the out of school rate, the relationships are reversed from above and are also intuitive. The pupil-teacher ratio (D) and the student-classroom ratio (E) are positively related to the 
out of school rate (less crowded school settings exist in areas where school attendance is high), while the school infrastructure variables (F)-(I) are negatively related to the out of school rate (better-provisioned school settings exist in areas where school attendance is high).

Having looked at the bivariate correlations we move to the regression analysis to isolate the impact of individual input measures on our outcomes of interest. Our estimating equation is the following:

$$
\begin{aligned}
(\text { Learning Outcome })_{s t}= & \alpha+\beta_{1}(\text { Pupil }- \text { Teacher Ratio })_{\text {st }}+\beta_{2}(\text { Student }- \text { Classroom Ratio })_{\text {st }} \\
& +\beta_{3}(\text { Drinking Water })_{s t}+\beta_{4}\left({\text { Girl's Toilet })_{s t}}\right. \\
& +\beta_{5}(\text { Classrooms in Good Condition })_{s t}+e_{i s t}
\end{aligned}
$$

In the equation above $\mathrm{s}$ is state and $\mathrm{t}$ is year. We use data on 20 major states over a period of 6 years. Due to missing data for some states in some years, our panel is unbalanced and the number of observations is less than 120 . We use three alternative dependent variables: 1) Proportion of children who can read a long paragraph (Table 2); 2) Proportion of children who can solve a division problem (Table 3); 3) Out of school rate (Table 4). We exploit cross-state and over time variations to identify the effects of independent variables on the dependent variables of interest. We use state fixed effects to control for any timeinvariant state characteristics and time fixed effects to control for any time trends arising from macroeconomic shocks or national policies that affected all states uniformly.

Table 2 provides results on the determinants of Reading. The key results in table 2 are the following. Lower pupil-teacher ratio and availability of drinking water facility are significantly associated with higher reading attainment. However, the statistical significance of the above determinants of reading attainment goes away when year and state fixed effects are included suggesting that the results are driven by cross-state variation rather than withinstate variation.

Table 3 provides results on the determinants of Math attainment. The results are qual- 
itatively similar to those for Reading. The two regressors, pupil-teacher ratio and drinking water facility, which were found to be significant in the Reading regressions, have large coefficients but fail to be statistically significant at the conventional levels. Drinking water facility, however, turns out to be significant in the separate regression for girls.

Table 4 provides results on the relationship between out of school rate and measures of schooling inputs. Note from Table 4 that the availability of drinking water facility and well-maintained classrooms are significantly associated with lower out of school rate (higher school attendance). Regressions with time and state fixed effects show that states which have improved classrooms have lowered out of school rates. As well, states which have increased the percentage of schools with separate girls' toilet have improved the enrolment of both boy and girls.

As far as the implications of pupil-teacher ratio and student-classroom ratio for enrolment are concerned, we get some positive and some negative coefficients. Normally, we would expect states with high pupil-teacher ratio or student-classroom ratio to have bad quality schools and therefore enrolment should be lower. That is, the coefficients of pupil-teacher ratio and student-classroom ratio should be positive in Table 4. However, in cases of these variables there is a possibility of reverse causality. That is, states which succeed in increasing enrolments may have crowded schools because the hiring of teachers or building of classrooms has not gone at the same pace. We also observed this for the case of Bihar where the increased enrolment since 2007-08 (see Figure 1) was accompanied by a slight uptick in the pupil-teacher ratio since 2007-08 (see Figure 6).

To conclude this section, we found several measures of schooling inputs to be significantly correlated with our outcome measures. Having good schooling infrastructure has been found to be a significant determinant of teacher attendance in the cross-country study of Chaudhury et al. (2006). Therefore, improving schooling infrastructure should be a policy imperative of the government of Bihar. The first aim should be to close the gap with the median state on measures where Bihar is below the median and subsequently the aim should be to close 
the gap with the best performing state in India. Next, we turn our attention to a survey of the literature on education policies.

\section{Survey of Literature on Education Policies}

Kremer and Holla (2009) provide an excellent survey of education policies with a focus on randomized evaluations. In this section we draw upon their work and also summarize findings of papers that are not discussed in their survey.

\subsection{Increase Enrolments in Schools}

\subsubsection{Supply-Side Interventions}

Duflo (2001) studies the implications of a large school expansion program launched in Indonesia from 1973 to 1978. More than 61,000 primary schools were constructed-an average of two schools per 1000 children aged 5-14 in 1971. The school expansion program followed a general allocation rule-the number of schools to be constructed in each district was proportional to the number of children of primary school age not enrolled in school in 1972. During this period of rapid expansion of schools, the enrolment rate went up from $69 \%$ in 1973 to $83 \%$ in 1978 for children aged 7-12. Combining differences across regions in the numbers of schools constructed with differences across cohorts induced by the timing of the programs, Duflo estimated that each primary school constructed per 1000 children led to an average increase of 0.12 to 0.19 years of education and 1.5 to 2.7 percent increase in wages. The increase in years of education was brought about by increasing primary schooling. The estimated returns to education ranged from 6.8 to 10.6 percent.

From a policy perspective, it is worth bearing in mind that a school construction program like this takes a very long time to generate positive returns. This is because costs are incurred early on, whereas the benefits are spread over generations. 


\subsubsection{Demand-Side Interventions}

\section{Reduction in Cost of Schooling}

While economists generally agree that the reduced cost of access to health and education is likely to increase the usage of these services, there is a contrarian view that people are likely to value a good more if it commands a price compared to the case when it is given for free. Therefore, the usage may be higher in the former case. In the case of education, however, there is no empirical work supporting the contrarian view. All the papers described below support the view that reducing the cost of access to education improves schooling outcomes.

Kremer and Holla (2009) in their survey discuss the three randomized experiments that were undertaken in Kenya to measure the responsiveness of school participation to outof-pocket costs of schooling. The out-of-pocket expense in these studies was the cost of school uniforms which was about $\$ 6$ in 2002, a non-trivial amount considering that the per capita GDP was about $\$ 340$. The study by Kremer, Moulin, and Namunyu (2003) finds that students in the treatment schools where uniforms were given for free remained enrolled longer and advanced grades further than their counterparts in comparison schools. Since the program had other components as well, it was difficult to isolate the impact of school uniforms, although the authors claim that the other components didn't affect enrolment. The other two experiments were able to isolate the impact of uniforms. Evans, Kremer, and Ngatia (2008) find that free uniforms given to primary school students reduced their absence by one-third, or 6 percentage points, with larger effects (13 percentage points, or 64 percent) for students who lacked uniforms prior to the program. Similarly, Duflo, Dupas, Kremer, and Sinei (2006) find that providing free uniforms to sixth graders reduced the dropout rates. Interestingly, it also reduced the childbearing of girls.

Providing free textbooks is another way to reduce the out of pocket cost of schooling. In their extensive survey of the literature on the impact of school resources on educational outcomes, Glewwe et al. (2011) come across 60 estimates from 21 different studies on the 
impact of textbooks and workbooks on learning outcomes. Out of the 60 estimates, 36 are positive and 26 are significantly positive, the number of significantly negative estimates is 4 . Thus, on balance the evidence in favor of providing textbooks/workbooks to enhance learning outcomes is strong. One of the prominent studies that didn't find free textbooks to have a positive effect on test scores is Glewwe, Kremer and Moulin (2007). Digging deeper, they find that the test scores of the strongest students did increase, which suggests a mismatch between the curriculum and the needs of the majority of students.

While subsidizing school uniforms or textbooks can reduce the direct cost of schooling, there is an opportunity cost of schooling coming from the foregone earning opportunities of children coming from poor families. An intervention that reduced the opportunity cost of schooling is the conditional cash transfer program in Mexico called PROGRESA. The program provided cash grants to families linked to the school attendance of children. According to Schultz (2004) this program had several desirable effects. In addition to increasing school attendance, the program also increased the transition rate from elementary school to junior secondary school. Interestingly, the repetition rate decreased for children in grade 1 and 2 who were not yet eligible for benefits, suggesting positive spillovers.

School meals can also be thought of as conditional transfer program because the meal is provided to only children who are present in school. Kremer and Vermeersch (2004) find that a school feeding program in preschools in Kenya had a positive effect on attendance.

\section{Merit Scholarship}

Experimental evidence from developing countries suggests that in some cases merit scholarship induces students to work hard. One such intervention was in Western Kenya. This intervention provided grade 6 girls a two year award consisting of free school supplies for one

year, and a public recognition at an awards assembly. The student had to score in the top 15 percent of their district exam to qualify for this award. In an evaluation of this program Kremer, Miguel, and Thornton (2009) find that the test scores of eligible girls increased 
by 0.19 standard deviations and the gains were more pronounced in larger and prosperous districts. In addition to the impact on test scores, student absenteeism went down as well. The authors also find positive spillovers of this intervention on students not eligible for this program.

\section{Information Provision on Returns to Schooling and Job Opportunities}

If the actual returns to schooling are greater than the perceived returns, then providing information on the returns to schooling can potentially increase participation in school. Using survey data from Dominican Republic for class 8th male students Jensen (2010) finds that the measured economic returns to secondary schooling exceed the returns perceived by students. When students are provided information on the measured returns to schooling in randomly selected schools, the average years of completed schooling goes up by $0.20-0.35$ over the next four years compared to children in other schools. This study also finds that the residential segregation by income is one of the factors why students underestimate returns to education. A policy implication of these findings is to stimulate demand by information campaigns about returns to schooling. Such policies tend to require minimal fiscal expenditure.

Nguyen (2008) studies a program in Madagascar that informs students of class 4 and their parents about the earnings differences by the levels of education. The program led to increases in attendance and test scores. Another intervention was to have role models with high education from different income backgrounds talk about their life stories to the students from the treatment group. The intervention was effective in raising test scores if the role model came from a poor income background similar to the students.

\section{Health-Related Interventions}

In a widely cited paper, Miguel and Kremer (2004) study the impact of a randomized mass deworming program carried out in primary schools in Kenya. The program was very successful in reducing the absence rates of students not only in treatment schools but also in 
neighboring schools through spillover effects. One plausible explanation behind the positive spillover is the interruption of disease transmission both within and across schools.

A similar program was conducted in urban India where deworming and iron supplements were provided in the treatment pre-schools. Bobonis, Miguel, and Sharma (2004) report that the intervention reduced the absence rate with the results being more pronounced among girls and children from low socio-economic status areas.

Using temporal and spatial variation in the implementation of an iodine supplement program in Tanzania, Field, Robles and Torero (2007) find that the children who had been exposed to this program in utero completed more years of schooling than those who did not get the treatment in utero.

Bleakley (2007) presents historical evidence on the effectiveness of deworming campaign in the early 20th century United States in improving school enrolment, school completion, and increased wages.

\subsection{Improve School Quality}

In the education literature poor school quality is often blamed for low school attendance. Below we look at the empirical evidence on the subject.

\subsubsection{Teacher Inputs}

Improving teacher inputs can improve educational outcomes along both quantitative and qualitative dimensions. Chin (2005) studies one such program in India, namely Operation Blackboard. Under this program, the central government of India provided all primary schools a teaching- learning equipment packet consisting of blackboards, books, charts and teacher's manual. Another component of this program provided all one teacher primary schools an additional teacher. Using survey data Chin (2005) finds that there was a substantial misallocation of resources in the sense that teachers were not necessarily allocated to the schools where they were needed most. She doesn't find evidence of a decrease in class size 
either. One possible explanation is that the states which were getting additional teachers under this program slowed down their normal hiring. However, the teacher component of this program did lead to an increase in the primary school completion rate for the girls and the poor.

Duflo, Dupas, and Kremer (2007) study Kenya's Extra Teacher Program to see the impact of hiring a contract on test scores. While the program reduced the pupil-teacher ratio from 84 to 46 , there was no effect on students test scores in the treatment schools.

Banerjee, Jacob, Kremer, Lanjouw and Lanjouw (2005) study the impact of hiring an extra teacher on educational outcomes in one-teacher non-formal education centers in India. The results from this experiment suggest that this program increased girls' attendance by 50 percent but had no impact on the boys' attendance primarily because of the fact that 63 percent of the new hires were females while only 19 percent of the teachers in comparison schools were females. Consistent with the view that households are more likely to send a girl child to school if at least one teacher is of the same gender, the authors find smaller impact on girls' enrollment when the original teacher in the school was female.

In a recent paper, Chetty et al. (2011) link data on the random assignment of students and teachers in Tennessee to small class sizes in kindergarten to third grade to later life outcomes using Social Security and other administrative records. They demonstrate that while innate ability, as measured by test scores in early childhood, is strongly correlated with various indicators of well-being such as earnings at age 27, college attendance, home ownership, and retirement savings, students who were assigned to small classes were still significantly more likely to go to college. They also show that peer effects are important even at young ages since children who were assigned to high-quality class environments, as measured by having classmates with high test scores, had higher earnings. 


\section{Recruitment and Promotion}

Gordon, Kane and Staiger (2006) cite evidence from the U.S. that the distribution of performance of traditionally certified teachers is no different from alternatively certified or even uncertified teachers. Also, a teacher's performance in the first couple of years is a good indicator of his/her long term performance. Based on this evidence they advocate a new approach for improving teacher quality. They recommend moving away from raising the credential for entry (the traditional approach) and focusing instead on identifying good teachers directly and linking the rewards to effective teaching. Teaching effectiveness should be measured by a combination of things: student achievement (some measure of value added or average gain in performance), subjective evaluations by principals and peers, and parental evaluations. They recommend against evaluating teachers based on licensure status, degrees awarded or courses taken. They advocate a bonus for highly rated teachers willing to teach in high poverty schools. They also suggest making it harder to promote least effective teachers to tenured positions. One approach would be that teachers in the bottom quartile of effectiveness after two years would not qualify for tenure and not be allowed to continue teaching.

To get around the problem of evaluating teachers in early elementary grades or high schools where test scores are not available they make the following suggestion. A state could require probationary teachers to start teaching in grades four or five, where their performance could be measured using the test score data. They could also develop alternative evaluation systems for teachers in non tested grades and subjects where value added measures are not practical. As an example they cite Connecticut's Beginning Educator Support and Training (BEST) program in which teachers submit portfolios of their work including lesson logs, videotaped segments of teaching, examples of student work, and reflective commentaries on the goals during the lesson. Portfolios are scored by multiple external assessors with experience in the same area as beginning teachers. 


\section{Teacher Absenteeism}

Chaudhury et al. (2006) study the issue of teacher absenteeism using first hand data from 6 developing countries including India. Their data are based on surveys where the enumerators made unannounced visits to schools and primary health care centers. They found the average teacher absence rate across the 6 countries to be around 19\%. The number for India was $25 \%$. The welfare effect of teacher absence is particularly high in India because many schools are one-teacher schools and substitutes rarely replace absent teachers. In this event, the students simply mill around, are unproductive, go home or join another class, often of a different grade. Despite such a high rate of absenteeism, teachers are not held accountable in India. An even more vexing problem is that even when teachers are present, they are not necessarily teaching. The paper finds that in Indian government-run schools, only $45 \%$ of the teachers assigned to a school are actually engaged in teaching activity at a given point of time. In Kenya enumerators found that while teachers were absent from the class $27 \%$ times, they were absent from school only $20 \%$ of the time.

Despite the provision of punitive action against absenteeism, teachers are rarely fired in India. Out of the 3000 Indian government run schools in their sample, only one head teacher reported a case where a teacher was fired for repeated absence. This may partly be due to the fact that Indian teachers have the support of unions which are strong and politically influential.

Chaudhury et al. (2006) conduct a regression exercise to understand the correlates of teacher absence in their sample of countries. Among teacher characteristics, somewhat surprisingly, they find that higher salaries are not necessarily correlated with lower teacher absence. Some important teacher characteristics related to teacher's absence are as follows: more powerful teachers are absent more; men are absent more than woman; head teachers are absent more than regular teachers; better educated teachers appear to be absent more; and finally, teachers who were born in the same district where the school is located are less 
likely to be absent.

Among school characteristics, they find a strong effect of school infrastructure on teacher absenteeism. A one standard-deviation increase in the school infrastructure index (toilets, covered classroom, non-dirt floors, electricity, and a school library) is associated with a 2.7 percentage point reduction in absence. This relationship remains even for teachers on their first posting, suggesting that the reverse causality from bad/sanctioned teachers being sent to schools with poor infrastructure is not driving the results.

More frequent monitoring of schools by higher authorities reduces teacher absenteeism. Among community characteristics, they find significant effect of parental literacy on teacher absenteeism. The regression result shows that a 10 percentage point increase in the parental literacy rate reduces the predicted absence by more than one percentage point.

Chaudhury et al. (2006) also find that private school teachers are 8 percentage points less likely to be absent than public school teachers working in the same village. As well, contract teachers from local areas less likely to be absent in all 6 countries. Some experiments from Kenya and India suggest the effectiveness of contract teachers. However, it is not clear which characteristics of contract teachers were responsible for the success in Kenya and India. The following are some of the possible reasons: they came from the same community as parents meaning they could have faced effective sanctions outside the school environment; they were chosen by school committees rather than central bureaucracy; contract teachers had renewable contracts, and they could be fired.

In a study based on data from Kenya, Glewwe, Ilias, and Kremer (2008) find that absences are not primarily due to a few teachers being absent all the time, but many teachers being absent from 20 percent to 50 percent of the times, with median teacher being absent 14-19 percent of the time.

In their survey of teacher incentive programs, Glewwe, Holla, and Kremer (2008) report that the merit scholarship program for 6th grade girls in Kenya mentioned earlier also led to an increase in teacher attendance in the program schools by $4.8 \%$ points from a baseline 
of $84 \%$ suggesting a $30 \%$ decrease in absence. In addition to teachers being more motivated to teach if students were motivated, parental monitoring may have played a role as well. Parents in treatment schools would visit schools more frequently to monitor teachers and pressure them to work hard so that their daughters could win scholarships.

Glewwe, Holla, and Kremer (2008) also study the impact of "Tracking" in explaining absenteeism. Tracking happens when children are segregated into classes based on their pre-intervention achievement score. They found that civil service teachers in the "tracked" schools with extra contract teachers were 5.4 percent points more likely to be found in schools on a random day relative to counterparts in untracked schools with contract teachers. The results suggest that it is more pleasant to teach children with above median ability. This is also consistent with the evidence in Chaudhury et al. (2006) that work environment (as reflected in school infrastructure in their study) is a key determinant of teacher absenteeism.

\section{Policies Aiming to Reduce Absenteeism}

Duflo, Hanna, and Ryan (2007) use a randomized experiment to study whether giving teachers cameras equipped with a tamper proof date and time function and rewarding them for attendance had an impact on teacher absence. They find that teacher absence rate declined from 42 percent to 22 percent in treatment schools. The decline in absence was accompanied by a 30 percent increase in instruction time which resulted in increased student learning: the test scores in the treatment schools were 0.17 standard deviation higher than in the comparison schools. As well, the teachers in treatment schools were no less likely to teach conditional on being present than the teachers in comparison schools. Children in treatment schools obtained 2.7 more days of schooling per month. The program also resulted in higher test scores and increased the graduation rate to mainstream schools. The program was extremely cost effective because the per child cost of raising test scores by 0.1 standard deviation was only $\$ 3.58$.

In contrast to the above studies which show the effectiveness of incentives in reducing 
teacher absenteeism, Kremer and Chen (2001) find that the incentives failed to reduce teacher absence under a program in rural Kenya. Under this program headmasters were supposed to reward teachers for attendance with cash bonuses. However, headmasters ended up giving bonuses to all teachers regardless of attendance.

\subsubsection{Incentive Structure}

\section{Incentive Pay for Teachers}

One of the more controversial policies in the literature on education reforms is that of incentive pay for teachers. Opponents of incentive pay schemes argue that teaching is inherently different from other jobs because the output of a teacher is not marketed. This makes it extremely difficult to measure the performance of a teacher. As well, since teachers work as a team creating performance based awards for individual teachers can vitiate the atmosphere of cooperation in schools. Finally, problems arise due to multitasking. That is, a teacher's performance is multi-dimensional, and tying the incentives to certain easy to measure dimensions of performance such as student test scores can result in "teaching to the test" at the cost of overall learning of students. However, supporters of incentive pay argue that advances in data systems allow more precise estimation of "value added" which can be used to design performance pay schemes. In the U.S. the department of education has created a competitive grant program to encourage states to develop databases that support value added measures (see Podgursky and Springer, 2007). If teachers work in teams then group incentive programs can work better than individual incentives. As far as the multitasking problem is concerned, the solution may lie in linking the incentives to a broader set of outcomes rather than just test scores. Finally, the advocates of merit pay argue that even if performance pay does not raise student achievement it may improve the overall quality of teachers through a positive selection effect. That is, it may attract people with higher ability into the teaching profession and may induce those with lower ability to either leave or work really hard to improve. 
Despite the controversy over merit pay, several school districts and states in the U.S. have started using merit pay schemes. Several states in the US have begun to use merit pay for teachers. In 1999 the city of Denver started a new teacher pay program linked to student performance and professional evaluations. In 2006 the state of Texas created the largest pay for performance program in the U.S. The state of Florida requires school districts to earmark at least 5 percent of the total salary pool for merit pay (see Table 2 in Podgursky and Springer (2007) for a comprehensive list of merit pay schemes in the U.S.)

Despite the controversy over merit pay, several school districts and states in the U.S. have started using merit pay schemes. In 1999 the city of Denver started a new teacher pay program linked to student performance and professional evaluations. In 2006 the state of Texas created the largest pay for performance program in the U.S. The state of Florida requires school districts to earmark at least $5 \%$ of the total salary pool for merit pay (see Table 2 in Podgursky and Springer (2007) for a comprehensive list of merit pay schemes in the U.S.)

Podgursky and Springer (2007) also provide a survey of the literature assessing the effectiveness of performance pay programs in the U.S. as well as outside the U.S. They nicely summarize the literature in Table 3 of their paper according to which most studies (both experimental and non-experimental) find the performance pay to have a positive impact on student achievement. Below we discuss some of these studies in detail.

Lavy (2002) estimates the impact of a group incentive program carried out non-randomly in 62 secondary schools in Israel in 1995. The objective of this intervention was to improve the performance of high-school graduates in their matriculation exams and to reduce the dropout rates in secondary schools. To get an award a school had to finish in the top third of the participating schools. The award ranged from $\$ 13,250$ to $\$ 105,000$. Two-thirds of the award amount was distributed among the teachers as salary bonuses. The awards were distributed equally among all teachers in the winning schools. The resulting bonuses ranged from $\$ 250$ to $\$ 1000$. The remainder third of the award was used to improve all-faculty 
facilities. The program increased the average test scores and reduced the dropout rates in the participating schools relative to the non- participating schools in the comparison group.

Lavy (2004) examines the results of an individual teacher incentive program in Israel where each participating teacher was ranked on the basis of value added in student achievement. Out of 629 participating teachers, 302 were awarded salary bonuses which could range up to $30 \%$ of their base salary. Again, the program had a positive effect on the performance of participating teachers (both the winners of awards and the other participants) relative to the comparison group of teachers who didn't participate in the program. His cost effectiveness analysis suggests that the individual incentive programs were more cost effective than the group incentive programs.

Figlio and Kenny (2007) conduct a survey to collect information on frequency and magnitude of merit raises and bonuses, teacher evaluation, and teacher termination. Combining data from the National Education Longitudinal Survey (NELS) on schools, students, and their families with their own survey on teacher incentives the authors find a positive association between the use of individual teacher incentives and student achievement. That is, students learn more in schools where teacher are offered incentive pay. Given the crosssectional nature of the data used, the authors do not claim to have found a causal mechanism. That is, the observed positive association could be either due to the effect of incentives on student outcomes or simply because better schools are self-selecting to implement merit pay programs. Due to the non-experimental nature of the study, one cannot ascribe causality from performance pay to student achievement.

Ahn (2011) studies the school based incentive program in North Carolina and finds the incentive pay to have a positive effect on student achievement. He also finds evidence of free riding behavior among teachers: teachers in larger schools are less responsive to incentive pay than teachers in smaller schools.

Glewwe, Ilias, and Kremer (2008) find evidence of existing teacher incentive programs to be weak in Kenya with teacher absenteeism being $20 \%$. In a randomized trial where 
teacher incentive was linked to performance on a test, children in the treatment schools had higher test scores. However, the authors attribute this mainly to increased teacher effort in teaching to the test by conducting more test preparations. They didn't find any evidence of improvement in teacher attendance, homework assignment or any change in pedagogy in treatment schools. As a consequence students in the treatment schools didn't retain the gains after the program was discontinued. Therefore, this study provides evidence of short term gains leading to better test performance from a teacher incentive program linked to test scores, but no long term learning.

Muralidharan and Sundararaman (2011) perform a randomized experiment of teacher incentive pay scheme in the state of Andhra Pradesh in India. They devise two incentive schemes: individual bonuses and group bonuses. The average bonus was calibrated to $3 \%$ of the annual salary of teachers. They report results on the program after it was in effect for two years. They find that students in incentive schools performed better than in control schools on math and language tests. Interestingly, students in incentive schools also performed better on subjects for which there were no incentives suggesting positive spillover. Both incentive schools performed better at the end of the first year but only individual incentive schools performed better at the end of the second year. In another treatment they provided schooling inputs to some schools and found that schools with teacher incentives performed better than those which were provided more schooling inputs. Digging deeper, they find that the impact of the incentive program worked not through increased attendance but greater teaching effort conditional on being present. Finally, their cost-effectiveness analysis suggests that performance based incentives are more cost effective than schooling inputs.

Kingdon and Teal (2007) use data from 10 private and 20 government funded schools in India to examine the impact of payment of performance related pay on student achievement. They find evidence of performance related pay in private schools but not in government schools. They also find that after controlling for student ability, parental background and the resources available, student outcomes in private schools respond positively to performance 
related pay but not so in government schools. The authors suggest that it is the fear of losing a well-paid job that raises the effort level of teachers in private schools.

\subsubsection{Other Inputs and Pedagogical Changes}

\section{Increasing Non-Teacher Inputs}

Non teacher inputs include things like providing teaching materials such as blackboards, flipcharts etc. There seems to be a difference in the results coming from non-experimental and experimental studies as far as the non-teacher inputs are concerned. While the former suggest positive impact of non-teaching inputs on educational outcomes, the latter suggest otherwise. For example, Filmer and Pritchett (1999) estimate that non-teacher inputs have a marginal product per dollar that is 10 to 100 times higher than teacher inputs. However, this is at odds with the experimental evidence from Kenya reported in Glewwe, Kremer, Moulin, and Zitzewitz (2004) which finds that flipcharts presenting material from the science, math, or geography curriculum did not improve test scores.

Glewwe et al. (2011) review the evidence from 1990 to 2010 on the contribution of various school resources and infrastructure in improving learning outcomes and increasing educational attainment. Based on 43 high-quality studies that they identified, they find that having an adequately-equipped and well-functioning school, which means one with quality roofs, walls or floors, with usable desks, tables and chairs, and with a school library, appears to have a clear positive impact on test scores. In terms of teaching inputs, their summary shows that having teachers that are knowledgeable in the subjects that they teach, that provide tutoring, and that absent themselves from work less often matter for achievement in cognitive tests. They also find that school-building programs consistently raise students' time in school, which makes them more likely to finish at a higher grade. They find inconclusive results for all the other variables also thought to be good interventions, and they attribute this ambiguity to either sensitivity to the local context or a small effect size that is not easily detectable. 


\section{Pedagogical Changes}

Can changing the medium of instruction improve learning? This is the question studied by Roy (2004) using data from West Bengal, a state in India where the medium of instruction was changed from English to Bengali, the vernacular language, at the primary level in 1983. The aim was to make primary education more accessible to poorer and rural children. The policy had a positive impact on educational attainment (measured by years of schooling), with the effect being more pronounced for poorer children. However, the policy did not affect enrollment either in rural or in urban areas. Interestingly, there was an increase in expenditure on private tutoring among the households belonging to richest quartiles, implying that well-off parents were supplementing the education imparted to their children in public school by private tutoring. This suggests that the policy change was deemed by the rich to be lowering the quality of public education which needed to be compensated by increased private tutoring.

Kremer and Holla (2008) survey several studies on the effectiveness of pedagogical changes, both experimental and non-experimental, and find most of the interventions to be successful in improving learning outcomes. For example, a program that provided electronic machine or flash card based activities to help improve the teaching of English led to an increase in the English test scores of treated students.

Banerjee et al. (2005) report results of two randomized experiments carried out in urban slums in Mumbai and Vadodara in India to assess the effectiveness of a remedial education program aimed at children who were lagging behind in government schools. Young women from the community were hired to teach these students basic literacy and numeracy skills. The intervention increased the average test score of all children in the treatment schools by 0.14 standard deviations in the first year and 0.28 in the second year compared to the control schools. Also, the gains were largest for the weakest students some of whom were the direct beneficiaries of the program. For example, the gain for the children in the bottom third of 
the initial distribution was 0.40 standard deviation in the second year of the program.

In the second treatment, each child from the 4 th grade was provided two hours of computer time per week when students played educational games that reinforced their mathematical skills. The intervention increased the math score of children in treatment schools by 0.35 standard deviations in the first year and 0.47 in the second year compared to the control schools. In the case of both interventions, students continued to show improvements for at least one year after leaving the program.

The success of these programs suggests that it may be possible to carry out interventions to improve the quality of education in developing countries in a cost effective way and without fundamentally transforming the entire system.

\section{Community Participation}

Can greater community participation improve educational outcomes? With the aim of improving the quality of education, in year 2000 the state government of UP in India came up with the idea of Village Educational Council (VEC) with the following functions: monitoring performance of govt. school, reporting problems to higher authorities, requesting additional resources, deciding on the renewal of contract of community based teachers, recruiting new hires, allocating any additional resources for school improvement received from national education program.

Banerjee et al. (2008) conduct a randomized experiment in UP to test some ideas on the effectiveness of community participation, community monitoring of teachers, local control over hiring, or a system where schools compete for students. They devised 3 kinds of interventions. In the first one, the NGO workers organized meetings and informed villagers about the status of education in the village, quality of local schools, state mandated provisions for schools relating to student-teacher ratio, infrastructure, mid-day meals, and scholarships, local funds available for education, and the responsibilities of VECs. In the second intervention, in addition to everything in the first, they gave specific monitoring tool by actively 
encouraging and equipping communities to participate in testing to see if children can read and do math. And finally, in the third intervention, in addition to 1 and 2, they added a training component in which community volunteers with a grade of 10 or 12 education trained for 4 days to teach children how to read.

All 3 interventions failed to raise teacher attendance. They didn't lead to increased parental involvement either. The third intervention led to increased community participation in reading and significantly improved reading achievement. Children who attended reading camps were $22.3 \%$ points more likely to read letters, $23.2 \%$ points more likely to read a paragraph, $22.4 \%$ points more likely to read a story than the comparison groups.

\section{Education Policies in Bihar and the Road Ahead}

The government of Bihar has launched several policy initiatives to improve the status of education in Bihar. We provide details on these programs in an appendix. In this section we analyze some of those initiatives from the perspective of the literature survey done in the previous sections and make some policy recommendations of our own.

\section{Health Intervention}

In our literature survey we found the effectiveness of certain school based health interventions in improving educational outcomes. Dhaliwal et al. (2011) provide cost-effectiveness estimates for the deworming program carried out in Kenya and India. Based on the study of Kremer and Miguel (2004) from Kenya they estimate that per $\$ 100$ spent on deworming leads to 13.9 years of extra schooling, while Bobonis et al. (2004) study for India suggests that the iron fortification and deworming program led to 2.9 extra years of schooling per $\$ 100$ spent. Seeing the success of these programs in raising schooling, in addition to their direct health benefits, the government of Bihar launched a massive deworming program in primary schools all over the state between February and April 2011. It is estimated that 
over 17 million children were treated in the largest school-based deworming effort of its kind. No systematic evaluation of this program has been undertaken yet.

\section{Cost of Schooling}

As detailed in the appendix, the government of Bihar has undertaken several policy initiatives aiming to reduce the out of pocket expenses or cost of schooling. The programs we are talking about are: the free textbook program; free school uniform program; mid-day meal program; and the cycle program. As discussed in section 3, the existing literature generally finds evidence in support of the effectiveness of these programs in improving learning outcomes. However, two caveats are in order here. One, unlike the deworming program or the information campaign, the cost-effectiveness of these programs is less clear cut. Two, sometimes these interventions may not yield desirable results because the binding constraint may lie somewhere else. For example, in our quantitative exercise we noted that $30 \%$ of students in class VI cannot read a paragraph taken from a class II textbook. Clearly, if students cannot read, free textbooks may fail to raise their test scores. In this case, a more appropriate intervention would be remedial education for children lagging behind.

\section{Increasing Enrolment}

From the quantitative exercise performed in the paper we learnt that enrollment ratio at the upper primary level is quite low both in absolute terms and relative to other states in India. Any attempt to increase enrollment rate at the upper primary level needs to be accompanied by an increase in the number of upper primary schools fully staffed with teachers. According to ADRI (2011), the number of primary and upper primary schools nearly doubled between 2005-06 and 2008-09, however, Bihar has a huge shortage of teachers. To meet the teacher-pupil ratio norm of 1:30 mandated in the Education Act, Bihar needs 246000 more teachers against the current strength of approximately 354000. This would 
require an enormous expansion in the number of teachers in the state.

\section{Improving School Quality}

Among the schooling inputs found significant in explaining the educational outcomes in our quantitative exercise, drinking water facility came up significant. There are about 79781 primary schools in Bihar (ADRI, 2011). According to DISE, in 2009-10 about 10 percent of the primary schools in the state did not have a proper drinking water facility (see figure 8). The cost of providing drinking water facility in these schools will be approximately Rs. 400 million ${ }^{4}$. Similarly, at the upper primary level, roughly 3 percent (about 620 out of 20771) of the schools did not have drinking water facilities in 2009-10 and the cost of providing it would be about Rs. 31 million. To put these numbers in perspective, the total public expenditure on elementary education in Bihar in 2009-10 was Rs. 48310 million (source: ADRI (2011)). Therefore, the cost of ensuring drinking water facilities in all primary and upper primary schools would be less than $1 \%$ of the annual public expenditure on elementary education. Providing drinking water facilities in all schools should be a policy imperative not simply because of its cost-effectiveness, but because it also satisfies a basic human need which makes it a moral imperative as well.

Another schooling input that turned out to be important in determining the out of school rate is the availability of separate toilet facilities for girls. According to DISE, about 79 percent (63026 out of 79781 ) of the primary schools in the state lacked separate toilet facilities for girls (see figure 9). The cost of building a single person toilet facility in the remaining primary schools will be about Rs. 4412 million $^{5}$. Similarly, about 71 percent (about 14747 out of 20771) of the upper primary schools in the state do not have separate toilet facilities for girls. The cost of building separate toilets in these schools would be about

\footnotetext{
${ }^{4}$ According to government sources the approximate cost of installing one hand pump is Rs. 50000. However, this should be considered an upper bound because according to quotes from some private sources, the approximate cost of installing a hand pump is Rs. 15000.

${ }^{5}$ According to the government sources the approximate cost of installing a one person toilet is Rs. 70000 . The cost according to a private party is Rs. 35000 .
} 
Rs. 1032 million. Again, the cost of ensuring that every primary and upper primary school in the state has separate toilet facilities for girls would be about $11 \%$ of the annual public expenditure on elementary education. Even though this is a significant amount, it is an investment which will yield benefits for several years.

We would like to re-emphasize that ensuring drinking water and separate toilet for girls should be a policy imperative for the government of Bihar. One of the key insights of the extensive survey of the education literature by Glewwe et al. (2011) is that having an adequately-equipped and well-functioning school has a clear positive impact on educational outcomes. One cannot imagine an adequately equipped school without having such basic facilities as drinking water and separate toilet for girls. While on the subject of adequately equipped school, it is worth re-iterating that our quantitative exercise identified classrooms in good condition as a significant correlate of educational outcomes. As shown clearly in Figure 10, only about $60 \%$ of the primary schools in Bihar had classrooms in good conditions, and therefore, this is another area in need of immediate attention.

\section{Incentive Pay for Teachers}

The existing literature suggests that performance pay for teachers can help improve student achievement. However, in order to implement a performance pay scheme, a necessary pre-requisite is to develop data systems to link student performance with teacher effectiveness. Several states and school districts in the U.S. have established data systems which enable them to link student performance with the effectiveness of individual teachers over time. Dallas estimates that its value-added system, serving 160000 students, cost about $\$ 210,000$ to start up and now costs about $\$ 100,000$ per year to operate. This suggests that the costs are small roughly equal to $\$ 1.31$ per youth in startup cost and $\$ 0.62$ per youth in annual operating cost.

According to ADRI (2011), in 2009-10 the estimated number of children in the age group 6-14 was 24.07 million. Assuming the same set up and running cost per student as in Dallas, 
the total set up cost in Bihar would be $\$ 31.5$ million which at current exchange rate would be Rs. 1577 million. The operating cost would be less than Rs. 750 million per year. That is the one time cost of setting up a data system would be $3.02 \%$ of the annual public expenditure on primary education, while the running cost would be roughly $1.5 \%$. However, these numbers are clearly an upper bound because there has to be huge economies of scale in setting up a statewide system. As well, while the cost of computers, which is a tradable, is likely to be similar in the U.S. and India, the labor cost is much cheaper, and therefore, the cost of creating such a system should be much less in Bihar. In addition to allowing the implementation of performance pay schemes, such a data system will allow the administrators to track schools over time and carry out interventions, not necessarily performance pay, in poorly performing schools. It will also serve as a valuable tool for researchers in the field of education. Given the long term benefits of setting up such a data system, the government of Bihar could even attempt to get an international organization or a foundation to provide initial funding for it. Based on the annual budget report for the year 2011-12, the government of Bihar plans to spend Rs. 72.24 millions on centralized monitoring cum data center. This seems to be a step in the right direction; however, the details of this policy are not available yet.

\section{Information Campaign}

While surveying the literature on demand side policies we discussed the role of information provision regarding the returns to schooling and their impact on schooling attainment. In a recent paper looking at the cost effectiveness of alternative policies to increase schooling, Dhaliwal et al. (2011) find the information provision to be one of the most cost effective programs in terms of increasing schooling. Based on the work Nguyen (2008) they calculate that on average $\$ 100$ spent on the information program led to a 20.7 years of additional schooling, while the estimate of Jensen (2010) from Dominican Republic suggests that the increasing in schooling per $\$ 100$ spent is 3.1 years. Given the cost effectiveness of this policy, 
it should receive a priority status among policies aiming to increase the quantity of schooling.

\section{Other Policies}

In our survey in section 3 we also mentioned the success of conditional cash transfer programs in improving educational outcomes. Following the success of PROGRESA (now called Oportunidades) in Mexico, several other Latin American countries implemented similar programs. It would be worthwhile for the government of Bihar to conduct a randomized control trial of conditional cash transfer program along the lines of PROGRESA and then decide whether to scale it up depending on the results.

Another policy worth considering is enhancing the English skill of students. After the opening up of India to the forces of globalization, knowledge of English has become a valuable asset. A recent study by Azam, Chin and Prakash (2011) finds that hourly wages for men who speak fluent English are on average 34\% higher than men who do not speak English in India. The wage premium is $13 \%$ for men who speak little English over men who do not speak English. Also, there is heterogeneity in the returns to English-language skills with more experienced and more educated workers receiving higher returns. Given this, it would be a good idea for the schools in Bihar to emphasize the development of English-language skills. Given that most parents do not know/speak English, schools can play an important role in enhancing the English skills of children.

\section{Concluding Remarks}

Bihar has made significant progress in sending nearly all primary school age children to school. However, the enrolment rates at the upper primary level are still very low. Also, the news on the quality front is far from satisfactory as revealed in the performance on reading and math tests. Despite the recent attempts by the state government to hire a large number of teachers, the pupil-teacher ratio remains the highest in the country at 53 in 2009-10, far 
in excess of the national norm of 30 specified in the Education Act. The government has undertaken several policy initiatives to lower the cost of schooling such as free textbooks, free uniforms, mid-day meals, and free bicycles. However, much remains to be done in improving the schooling infrastructure. Only $60 \%$ of the schools have classrooms in good condition; $10 \%$ of the primary schools still lack drinking water facility; more than $70 \%$ of the primary and upper primary schools do not have separate girls' toilets. These are some areas of concern which should be of highest priority to the policy makers. We are encouraged by the government's efforts in going in for a massive school based deworming program in 2011.

Experimental research suggests that providing information about returns to schooling can encourage children to stay longer in school, and given the cost-effectiveness of this policy, the government of Bihar must seriously look into this policy option. More generally, understanding the determinants of household's decision to invest in education should be an important component of academic research and policy in the area of education which has tended to focus more on improving the quantity and quality of educational inputs.

Looking to the future, incentive pay for teachers can play an important role in improving the quality of education. However, to link student performance to teacher effectiveness, a statewide data system needs to be created. Such a data system will also help monitor the performance of schools and allow the administrators to take remedial action in failing schools. 


\section{References}

Ahn, Thomas. "The Missing Link: Estimating the Impact of Incentives on Effort and Effort on Production Using Teacher Accountability Legislation." Mimeo.

Angrist, Joshua, Eric Bettinger, and Michael Kremer. "Long-Term Educational Consequences of Secondary School Vouchers: Evidence from Administrative Records in Colombia." American Economic Review, 2006, 93 (3), pp 847-862.

Angrist, Joshua, Eric Bettinger, Erik Bloom, Elizabeth King, and Michael Kremer. "Vouchers for Private Schooling in Colombia: Evidence from a Randomized Natural Experiment." American Economic Review, 2002, 92 (5), pp 1535-1558.

Asian Development Research Institute. "Elementary Education in Bihar: Progress and Challenges." Manuscript, 2011.

Azam, M., A. Chin, and N. Prakash. "The Returns to English-Language Skills in India." Economic Development and Cultural Change, Forthcoming.

Banerjee, Abhijit, Rukmini Banerji, Esther Duflo, Rachel Glennerster, and Stuti Khemani. "Pitfalls of Participatory Programs: Evidence from a Randomized Evaluation in Education in India." National Bureau of Economic Research, Working Paper No. 14311, 2008.

Banerjee, Abhijit, Shawn Cole, Esther Duflo, and Leigh Linden. "Remedying Education: Evidence from two Randomized Experiments in India." National Bureau of Economic Research, Working Paper No. 11904, 2005.

Banerjee, Abhijit, Suraj Jacob, Michael Kremer, Jenny Lanjouw, and Peter Lanjouw. "Moving to Universal Education: Costs and Trade Offs." Massachusetts Institute of Technology, Manuscript, 2005. 
Bleakley, Hoyt. "Disease and Development: Evidence from Hookworm Eradication in the American South." Quarterly Journal of Economics, 2007, 122 (1), pp 73-117.

Bleakley, Hoyt. "Malaria Eradication in the Americas: A Retrospective Analysis of Childhood Exposure." American Economic Journal: Applied Economics, 2010, 2 (2), pp $1-45$.

Bobonis, Gustavo, Edward Miguel, and Charu Puri Sharma. "Iron Deficiency Anemia and School Participation." Abdul Latif Jameel Poverty Action Lab (J-PAL), Paper No. 7, 2004.

Chaudhury, Nazmul, Jeffrey Hammer, Michael Kremer, Karthik Muralidharan, and F. Halsey Rogers. "Missing in Action: Teacher and Health Worker Absence in Developing Countries." Journal of Economic Perspectives, 2006, 20 (1), pp 91-116.

Chetty, Raj, John Friedman, Nathaniel Hilger, Emmanuel Saez, Diane Schanzenbach, and Danny Yagan. "How Does Your Kindergarten Classroom Affect Your Earnings? Evidence from Project STAR." Quarterly Journal of Economics, 2011, 126 (4), pp 1593-1660.

Chin, Aimee. "Can Redistributing Teachers Across Schools Raise Educational Attainment? Evidence from Operation Blackboard in India." Journal of Development Economics, 2005, 78 (2), pp 384-405.

Dhaliwal, Iqbal, Esther Duflo, Rachel Glennerster, and Caitlin Tulloch. "Comparative Cost Effectiveness Analysis to Inform Policy in Developing Countries: A General Framework with Applications for Education." Abdul Latif Jameel Poverty Action Lab (J-PAL), Massachusetts Institute of Technology, Manuscript, 2011.

Duflo, Esther, Rema Hanna, Stephen Ryan. "Monitoring Works: Getting Teachers to Come to School." National Bureau of Economic Research, Working Paper No. 11880, 2007. 
Duflo, Esther, Pascaline Dupas, and Michael Kremer. "Peer Effects, Pupil-Teacher Ratios, and Teacher Incentives: Evidence from a Randomized Evaluation in Kenya." Manuscript, 2007.

Duflo, Esther, Pascaline Dupas, Michael Kremer, and Samuel, Sinei. "Education and HIV/AIDS Prevention: Evidence From a Randomized Evaluation in Western Kenya." World Bank Policy Research Working Paper No. 4024, 2006.

Duflo, Esther. "Schooling and Labor Market Consequences of School Construction in Indonesia: Evidence From an Unusual Policy Experiment." American Economic Review, 2001, 91 (4), pp 795-813.

Evans, David, Michael Kremer, and Muthoni Ngatia. "The Impact of Distributing School Uniforms on Children's Education in Kenya." Manuscript, 2008.

Field, Erica, Omar Robles, and Maximo Torero. "Iodine Deficiency and Schooling Attainment in Tanzania." Manuscript, 2007.

Figlio, David and Lawrence Kenny. "Individual Teacher Incentives and Student Performance." Journal of Public Economics, 2007, 91 (5-6), pp 901-914.

Filmer, Deon and Lant Pritchett "What Education Production Functions Really Show: A Positive Theory of Education Expenditures." Economics of Education Review, 1999, $18(2)$, pp 223-239.

Gleww, Paul, Eric Hanushek, Sarah Humpage, and Renato Ravina. "School Resources and Educational Outcomes in Developing Countries: A Review of the Literature From 1990 to 2010." National Bureau of Economic Research, Working Paper No. 17554, 2011.

Glewwe, Paul, Alaka Holla, and Michael Kremer. "Teacher Incentives in the Developing World." Manuscript, 2008. 
Glewwe, Paul, Michael Kremer and Sylvie Moulin. "Many Children Left Behind? Textbooks and Test Scores in Kenya." National Bureau of Economic Research, Working Paper No. 13300, 2007.

Glewwe, Paul, Michael Kremer, Sylvie Moulin, and Eric Zitzewitz. "Retrospective vs. Prospective Analysis of School Inputs: The Case of Flip Charts in Kenya." Journal of Development Economics, 2004, 74 (1), pp 251-268.

Glewwe, Paul, Nauman Ilias, and Michael Kremer. "Teacher Incentives in the Developing World." Manuscript, 2008.

Gordon, Robert, Thomas Kane, and Douglas Staiger. "Identifying Effective Teachers Using Performance on the Job." The Brookings Institution, Discussion Paper 2006-01, 2006.

He, Fang, Leigh Linden, and Margaret Leod. "Helping Teach What Teachers Don't Know: An Assessment of the Pratham English Language Program.", Manuscript, 2007.

Hoxby, Caroline. "Does Competition Among Public Schools Benefit Students and Taxpayers?" American Economic Review, 2000, 90 (5), pp 1209-1238.

Jamison, Dean, Barbara Searle, Klaus Galda, and Stephen Heyneman. "Improving Elementary Mathematics Education in Nicaragua: An Experimental Study of the Impact of Textbooks and Radio on Achievement." Journal of Educational Psychology, 1981, 73 (4), pp 556-567.

Jensen, Robert. "The (Perceived) Returns to Education and the Demand for Schooling." Quarterly Journal of Economics, 2010, 125 (2), pp 515-548.

Kingdon, Geeta and Francis Teal. "Does Performance Related Pay for Teachers Improve Student Performance? Some Evidence from India." Economics of Education Review, 2007, 26 (4), pp 473-486. 
Kirschner, Paul, John Sweller, and Richard Clark. "Why Minimal Guidance During Instruction Does Not Work: An Analysis of the Failure of Constructivist, Discovery, ProblemBased, Experiential, and Inquiry-Based Teaching." Educational Psychologist, 200641 (2), pp 75-86.

Kouskalis, Eric. "Does Not Compute: The Introduction of New Technologies to South African and Namibian Classrooms." Harvard Undergraduate Thesis, 2008.

Kremer, Michael and Alaka Holla. "Improving Education in the Developing World: What Have We Learned from Randomized Evaluations?" in Kenneth J. Arrow and Timothy F. Bresnahan, eds., Annual Review of Economics, Volume 1, 2009. Palo Alto, California: Annual Reviews.

Kremer, Michael and Christel Vermeersch. "School Meals, Educational Achievement, and School Competition: Evidence from a Randomized Evaluation." Manuscript, 2004.

Kremer, Michael and Daniel Chen. "An Interim Program on a Teacher Attendance Incentive Program in Kenya." Manuscript, 2001.

Kremer, Michael, Edward Miguel, and Rebecca Thornton. "Incentives to Learn." Review of Economics and Statistics, 2009, 91 (3), pp 437-456.

Kremer, Michael, Sylvie Moulin, and Robert Namunyu. "Decentralization: A Cautionary Tale." Manuscript, 2003.

Lavy, Victor. "Evaluating the Effect of Teachers' Group Performance Incentives on Pupil Achievements." Journal of Political Economy, 2002, 110 (6), pp 1286-1317.

Lavy, Victor. "Performance Pay and Teachers' Effort, Productivity and Grading Ethics." National Bureau of Economic Research, Working Paper No. 10622, 2004.

Miguel, Edward and Michael Kremer. "Worms: Identifying Impacts on Education and Health in the Presence of Treatment Externalities." Econometrica, 2004, 72 (1), pp 159-217. 
Muralidharan, Karthik and Venkatesh Sundararaman. "Teacher Performance Pay: Experimental Evidence From India." Journal of Political Economy, 2011119 (1), pp 39-77.

Nguyen, Trang. "Information, Role Models and Perceived Returns to Education: Experimental Evidence From Madagascar." Job Market Paper, Massachusetts Institute of Technology.

Podgursky, Michael and Matthew Springer. "Teacher Performance Pay: A Review." Journal of Policy Analysis and Management, 200726 (4), pp 909-950.

PROBE Team. "Public Report on Basic Education in India." New Delhi: Oxford University Press, 1999.

Roy, Joydeep. "The Impact of Lowering of Academic Standards on Educational Outcomes: Evidence From an Unusual Policy in India." Manuscript, 2004.

Schultz, T. Paul. "School Subsidies For The Poor: Evaluating the Mexican Progresa Poverty Program." Journal of Development Economics, 2004, 74 (1), pp 199-250. 
Figure 1: Out of school rate, children 6-14 years old (\%)

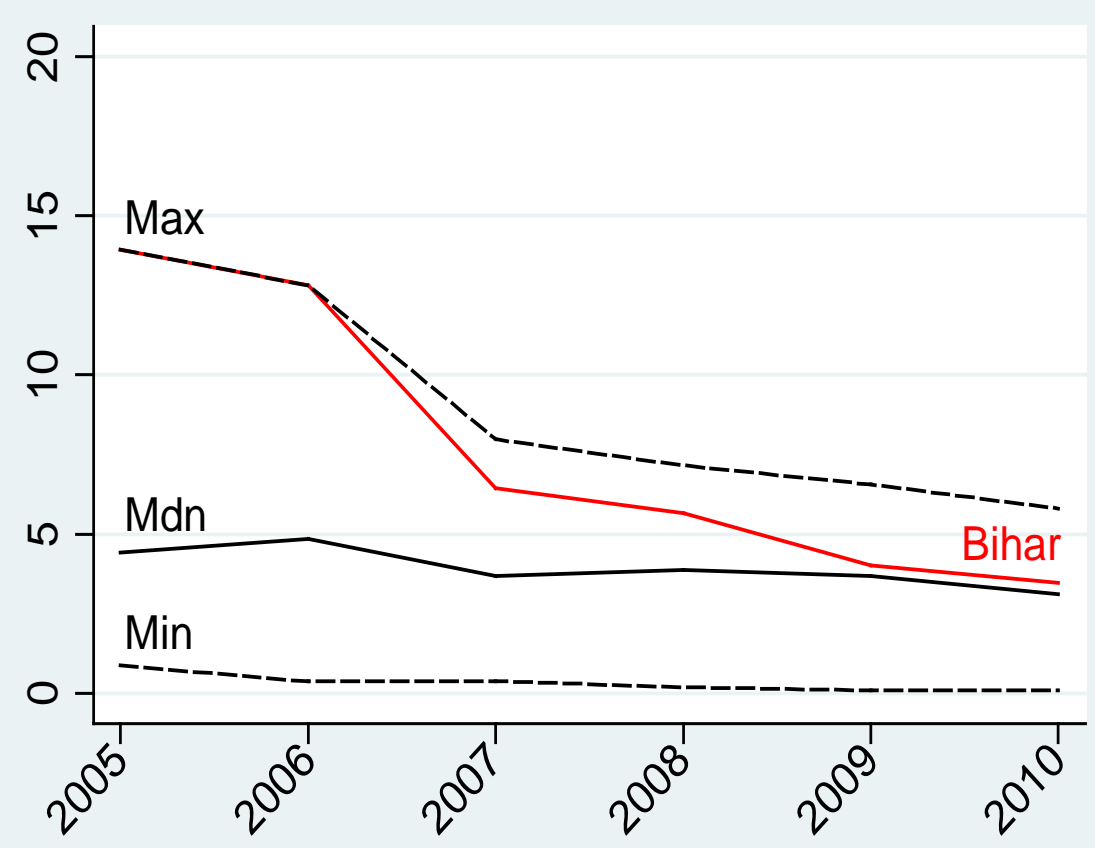

Note: The minimum, median, and maximum are computed across the 20 most populous states in India. Source: ASER, various years. See other notes in Table 1. 
Figure 2: Net enrolment ratio, primary schools

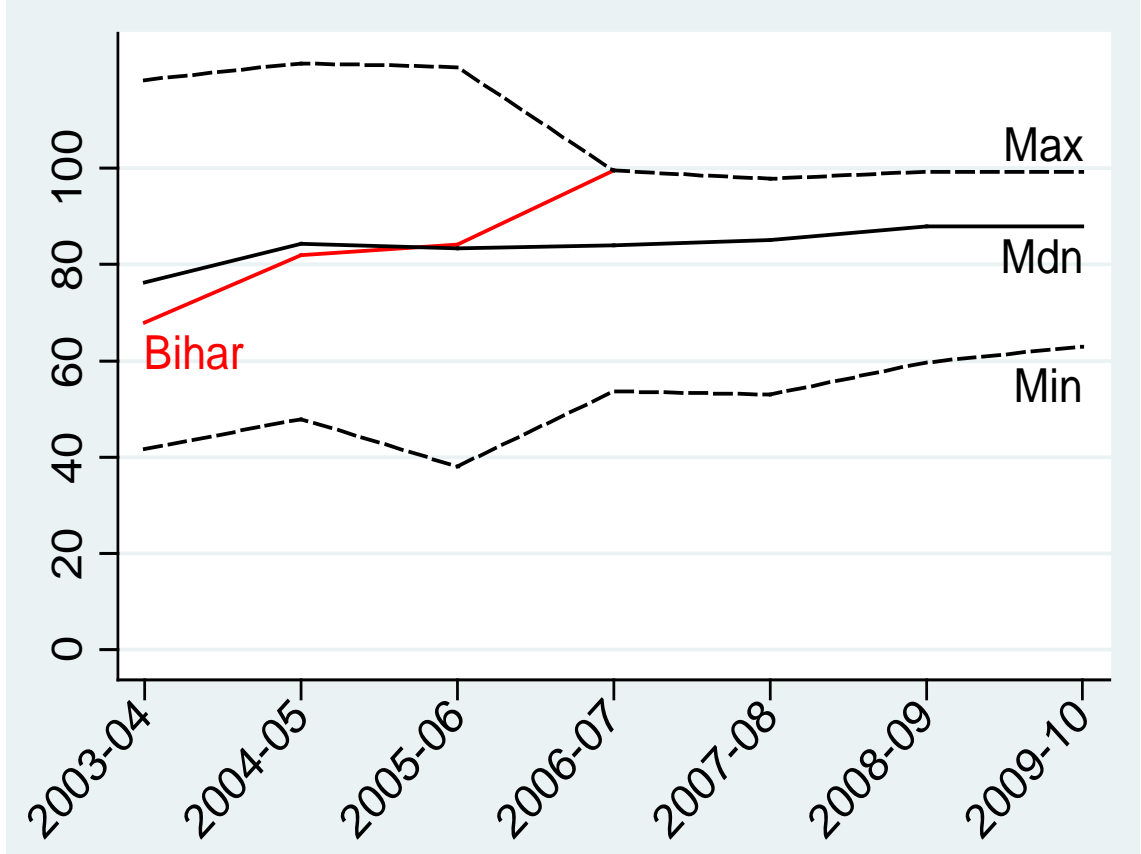

Note: The minimum, median, and maximum are computed across the 20 most populous states in India. Source: ASER, various years. See other notes in Table 1. 
Figure 3: Net enrolment ratio, upper primary schools

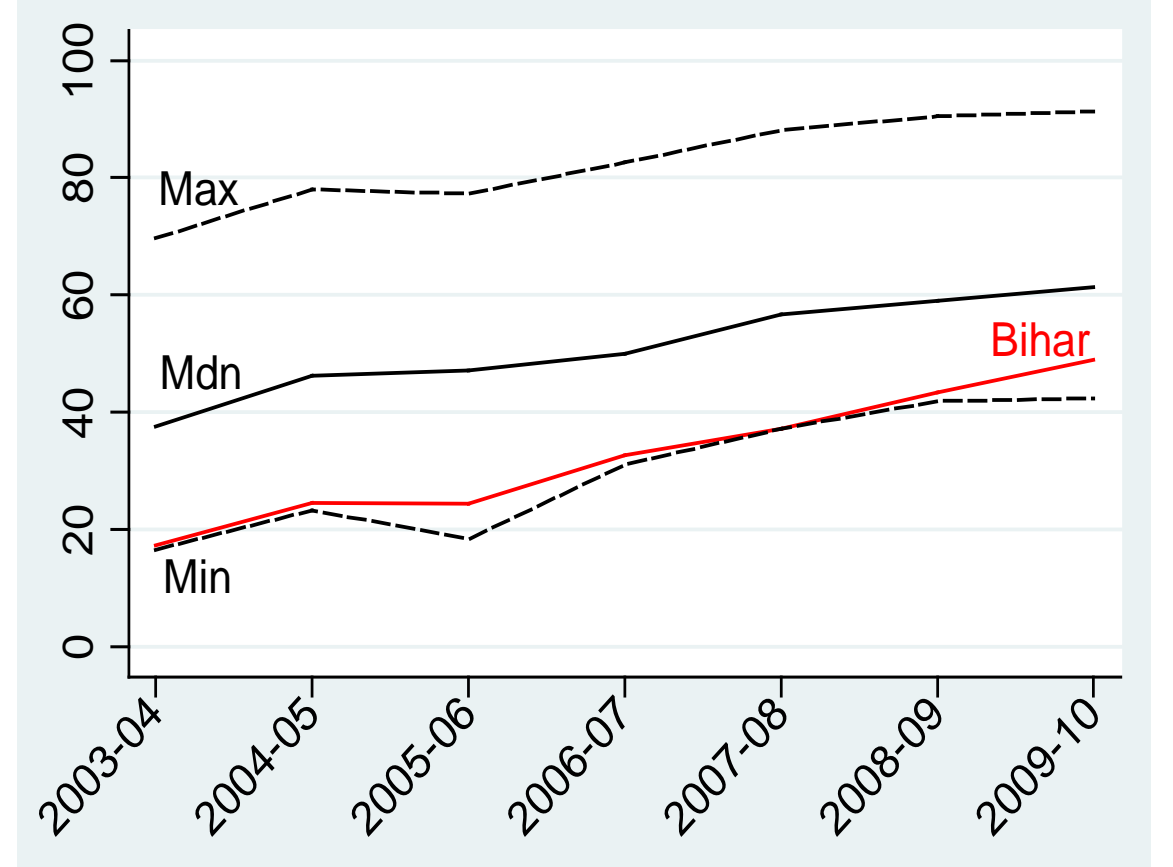

Note: The minimum, median, and maximum are computed across the 20 most populous states in India. Source: ASER, various years. See other notes in Table 1. 
Figure 4: Percentage of children who can read long paragraph (6-14 years old)

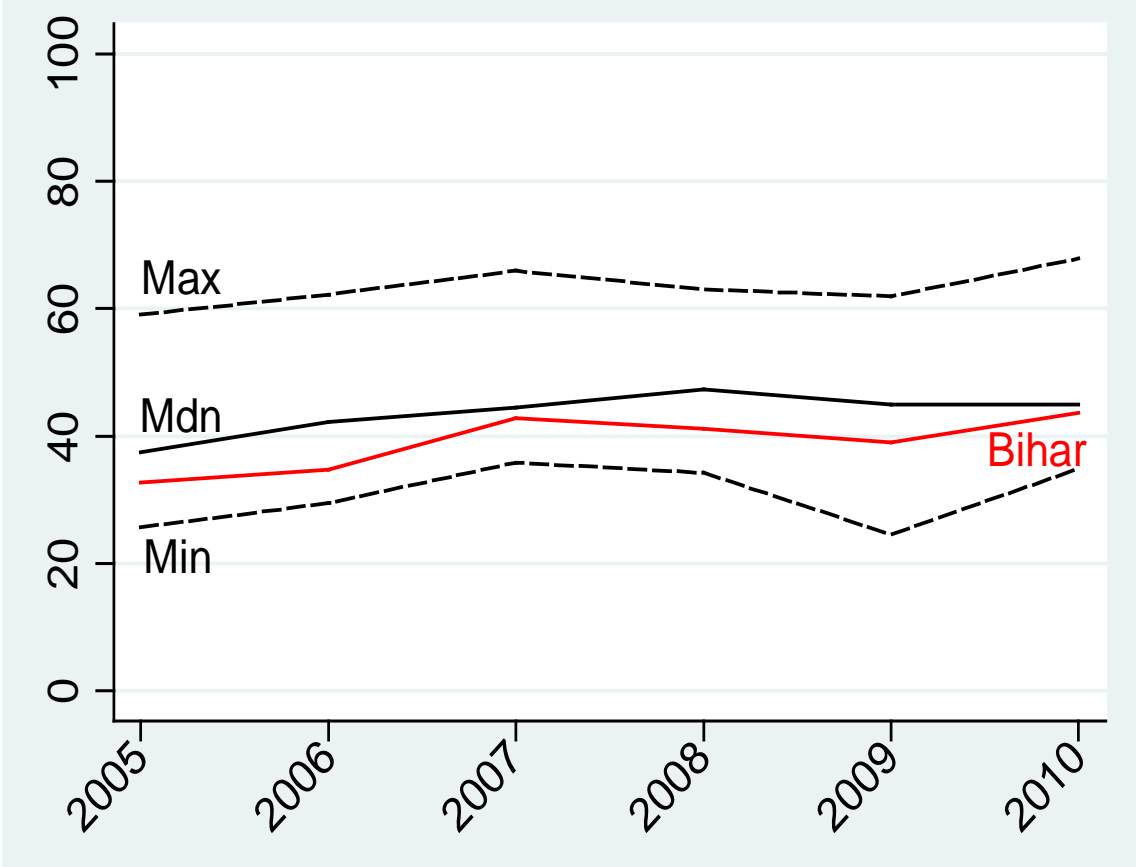

Note: The minimum, median, and maximum are computed across the 20 most populous states in India. Source: ASER, various years. See other notes in Table 1. 
Figure 5: Percentage of children who can solve division problem (6-14 years old)

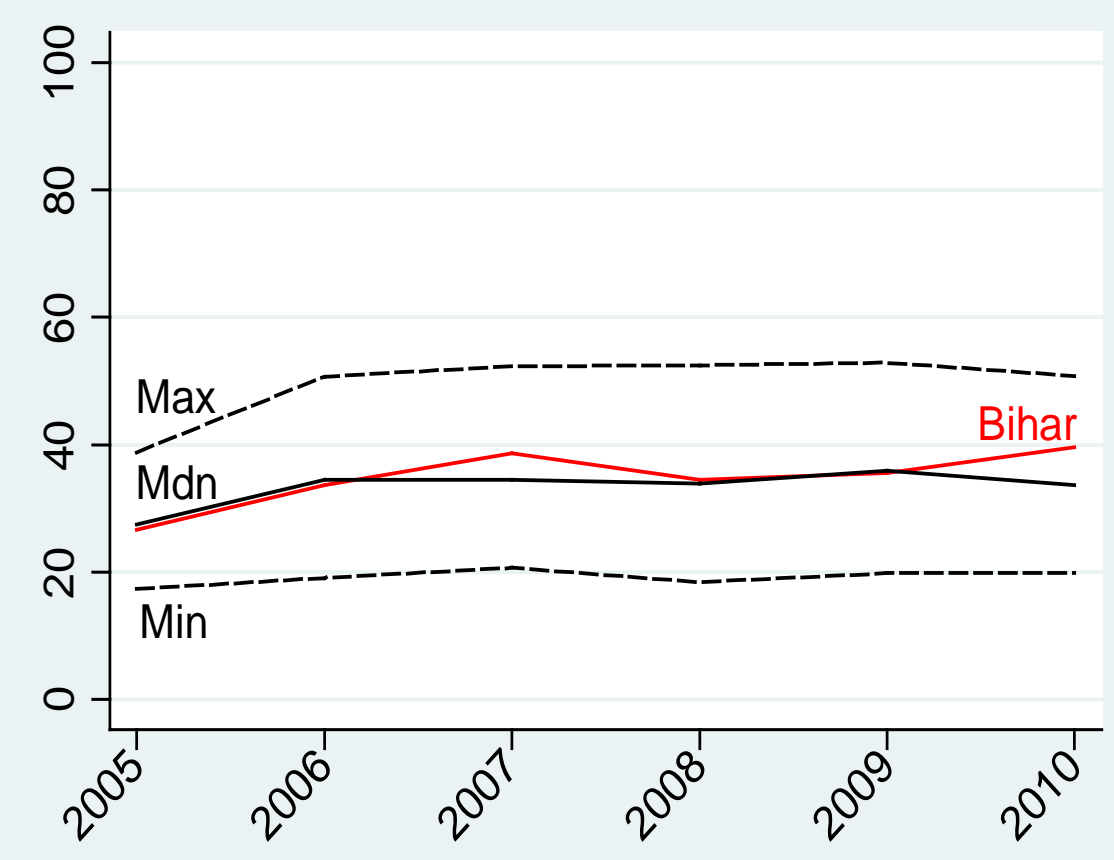

Note: The minimum, median, and maximum are computed across the 20 most populous states in India. Source: ASER, various years. See other notes in Table 1. 
Figure 6: Pupil-teacher ratio (primary schools)

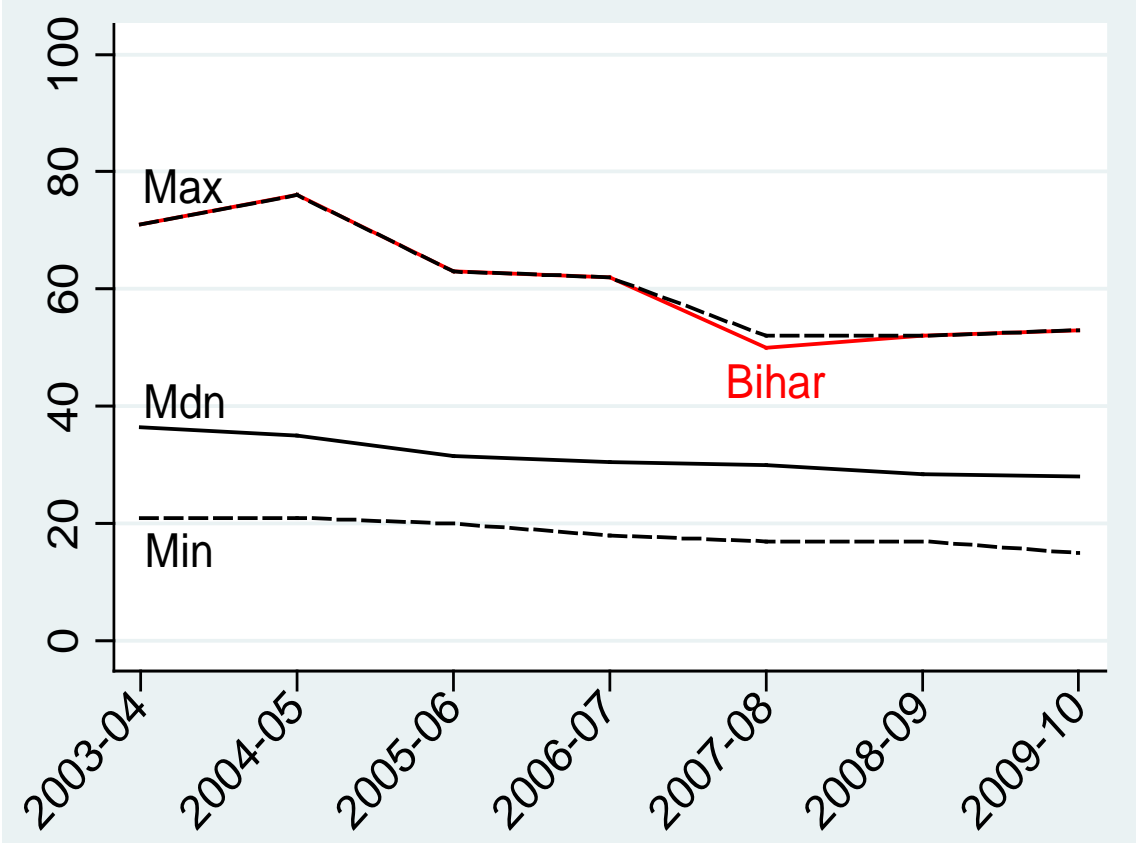

Note: The minimum, median, and maximum are computed across the 20 most populous states in India. Source: ASER, various years. See other notes in Table 1. 
Figure 7: Student-classroom ratio (primary schools)

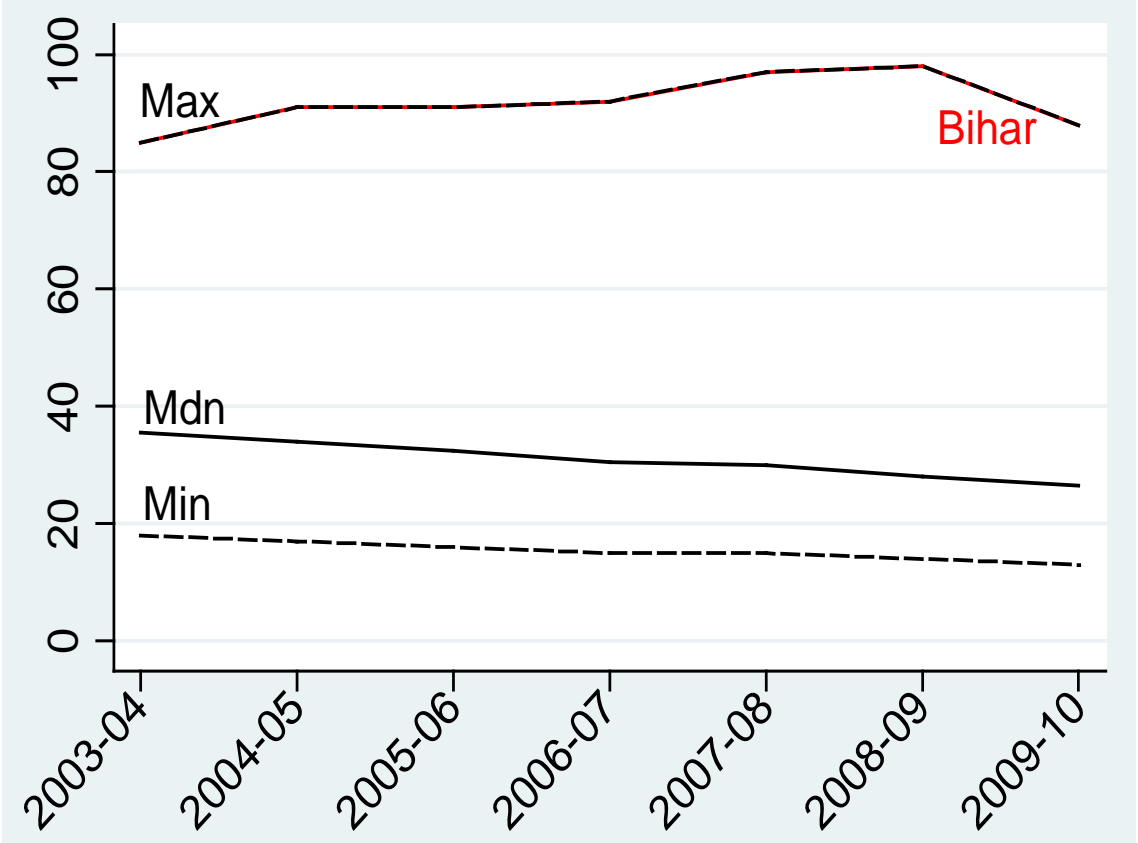

Note: The minimum, median, and maximum are computed across the 20 most populous states in India. Source: ASER, various years. See other notes in Table 1. 
Figure 8: Percentage of schools with drinking water facility (primary level)

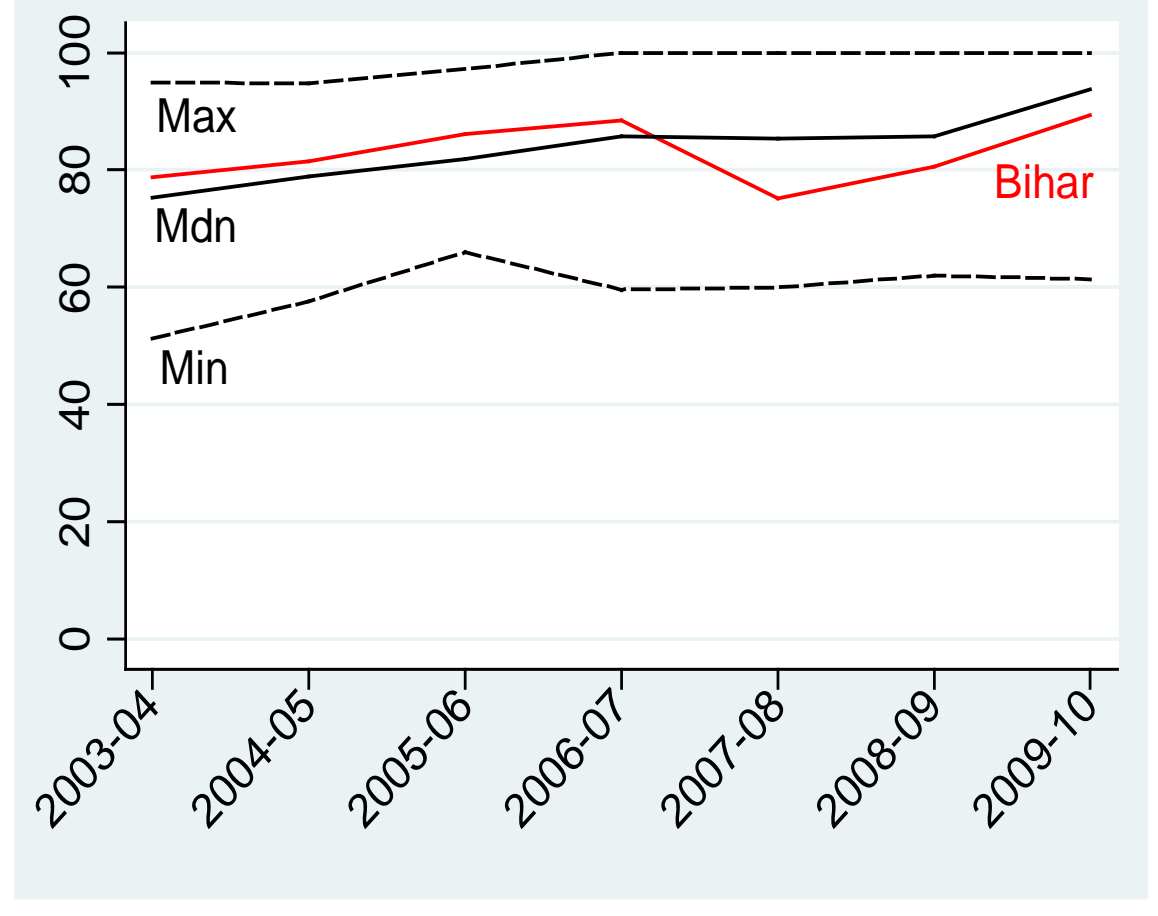

Note: The minimum, median, and maximum are computed across the 20 most populous states in India. Source: ASER, various years. See other notes in Table 1. 


\section{Figure 9: Percentage of schools with girls' toilet (primary level)}

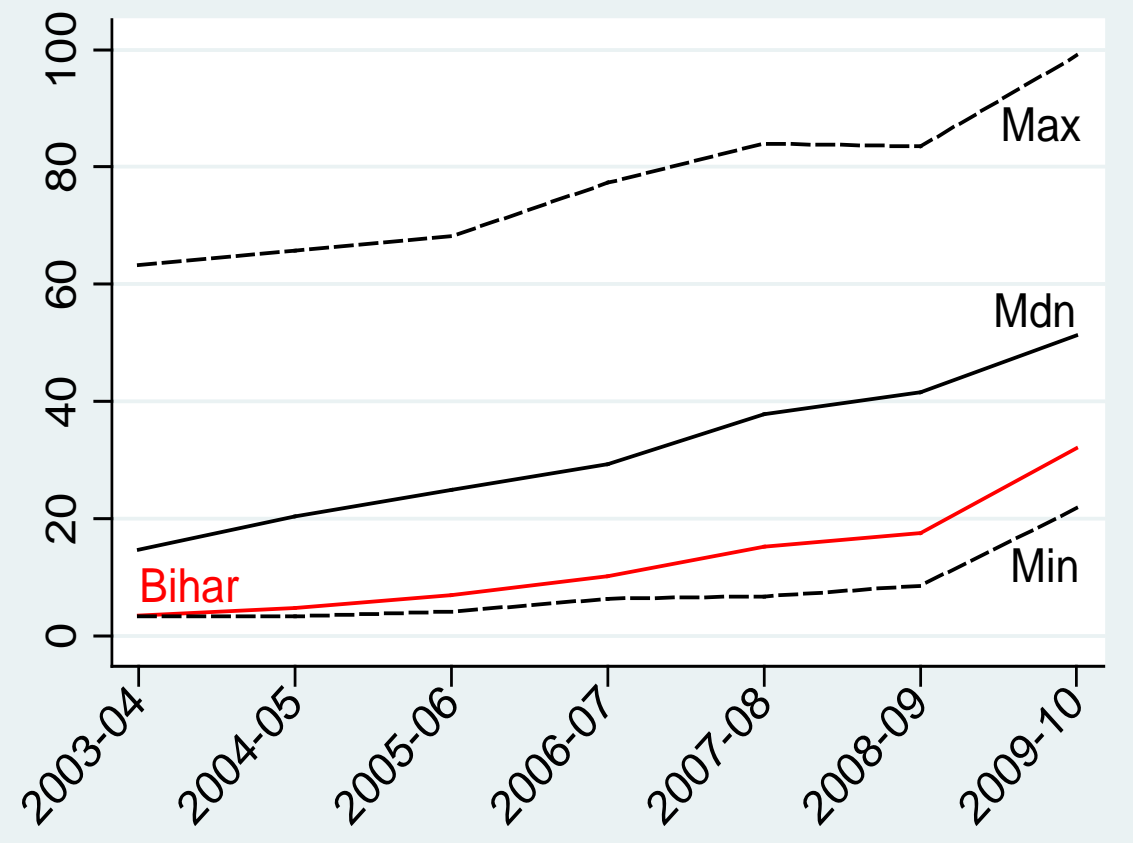

Note: The minimum, median, and maximum are computed across the 20 most populous states in India. Source: ASER, various years. See other notes in Table 1. 
Figure 10: Proportion of classrooms in good condition (primary level)

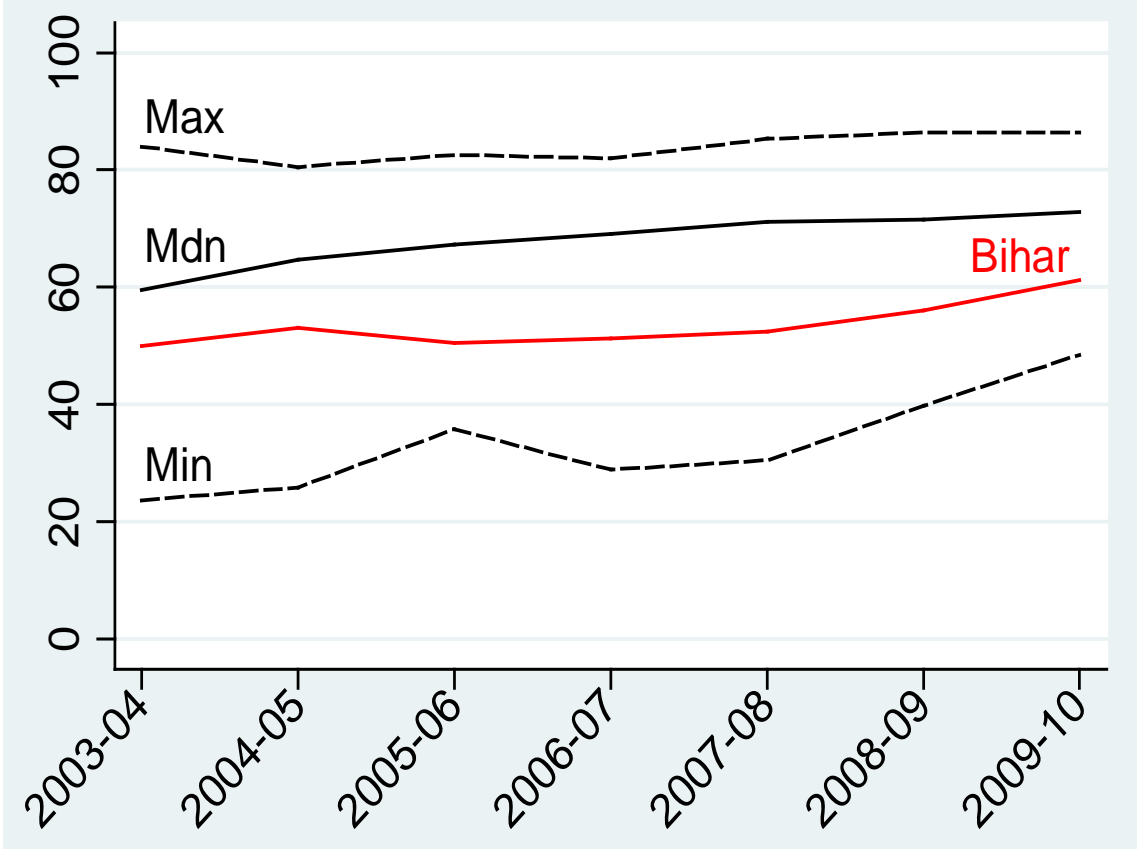

Note: The minimum, median, and maximum are computed across the 20 most populous states in India. Source: ASER, various years. See other notes in Table 1. 


\section{Table 1: Correlation Matrix (N=119)}

\begin{tabular}{r|cccccccc} 
& $(\mathrm{A})$ & $(\mathrm{B})$ & $(\mathrm{C})$ & $(\mathrm{D})$ & $(\mathrm{E})$ & $(\mathrm{F})$ & $(\mathrm{G})$ & $(\mathrm{H})$ \\
\cline { 2 - 11 } \% Can read long paragraph (A) & 1.00 & & & & & & & \\
\% Can solve division problem (B) & 0.82 & 1.00 & & & & & & \\
Out of school rate (C) & -0.53 & -0.32 & 1.00 & & & & & \\
Pupil-teacher ratio (D) & -0.38 & -0.11 & 0.57 & 1.00 & & & & \\
Student-classroom ratio (E) & -0.36 & -0.12 & 0.52 & 0.85 & 1.00 & & & \\
\% Schools with drinking water facility (F) & 0.40 & 0.36 & -0.37 & 0.08 & -0.19 & 1.00 & & \\
\% Schools with girls' toilet (G) & 0.34 & 0.24 & -0.38 & -0.03 & -0.30 & 0.69 & 1.00 & \\
\% Classrooms in good condition (H) & 0.13 & 0.04 & -0.37 & -0.08 & -0.29 & 0.40 & 0.57 & 1.00
\end{tabular}

Source: ASER (2005-2010) for variables A-C, and DISE (2004-05 to 2009-10) for variables DH. Computed using data from the following 20 most populous states: Andhra Pradesh, Assam, Bihar, Chhattisgarh, Gujarat, Haryana, Himachal Pradesh, Jharkhand, Karnataka, Kerala, Madhya Pradesh, Maharashtra, Orissa, Punjab, Rajasthan, Tamil Nadu, Tripura, Uttar Pradesh, Uttaranchal, and West Bengal. ASER data for Madhya Pradesh was missing in 2010. To ensure consistency across time, variables A-C refer to data in the ASER sample for all children 6-14 years old, while variables D-H refer to data reported in the DISE for all primary-only schools. 


\section{Table 2: Determinants of Reading Attainment}

\begin{tabular}{lcc|cc|cc} 
& \multicolumn{5}{c}{ Dependent variable: Proportion who can read long paragraph } \\
\cline { 2 - 7 } Independent variables: & \multicolumn{2}{c}{ All } & \multicolumn{2}{c}{ Boys } & \multicolumn{2}{c}{ Girls } \\
& $(1)$ & $(2)$ & $(3)$ & $(4)$ & $(5)$ & $(6)$ \\
\hline Pupil-teacher ratio & $-0.5419 * *$ & 0.1403 & -0.2211 & -0.0010 & -0.3614 & -0.0001 \\
& $(0.232)$ & $(0.205)$ & $(0.175)$ & $(0.086)$ & $(0.212)$ & $(0.085)$ \\
Student-classroom ratio & 0.1627 & 0.0014 & 0.0251 & 0.0022 & -0.0055 & 0.0020 \\
& $(0.107)$ & $(0.074)$ & $(0.073)$ & $(0.075)$ & $(0.098)$ & $(0.085)$ \\
\% Schools with drinking water facility & $0.3561 *$ & 0.0028 & $0.3248 *$ & 0.1165 & $0.3909 * *$ & 0.1588 \\
& $(0.170)$ & $(0.146)$ & $(0.167)$ & $(0.090)$ & $(0.154)$ & $(0.097)$ \\
\% Schools with girls' toilet & 0.0654 & 0.0392 & 0.0161 & -0.0339 & 0.0284 & -0.0276 \\
& $(0.078)$ & $(0.080)$ & $(0.075)$ & $(0.051)$ & $(0.079)$ & $(0.039)$ \\
\% Classrooms in good condition & -6.7212 & -15.4403 & -0.0321 & -0.1382 & -0.0755 & -0.0679 \\
& $(11.615)$ & $(11.405)$ & $(0.111)$ & $(0.080)$ & $(0.118)$ & $(0.082)$ \\
Constant & $28.8727 *$ & $45.8596 * *$ & $28.4981 *$ & $46.5593 * *$ & $31.2813 * *$ & $38.8758 * *$ \\
& $(14.160)$ & $(17.183)$ & $(13.907)$ & $(9.649)$ & $(12.927)$ & $(10.309)$ \\
\hline Year and state fixed effects & No & Yes & No & Yes & No & Yes \\
Adj. R-squared & 0.327 & 0.786 & 0.225 & 0.853 & 0.384 & 0.895 \\
No. of observations & 119 & 119 & 99 & 99 & 99 & 99
\end{tabular}

Note: Standard errors were clustered at the state level and shown above in parentheses. Significance indicated at the following confidence levels: * 90 percent, ** 95 percent, *** 99 percent. See other notes in Table 1. The number of observations is smaller in columns 3-6 because ASER data that is disaggregated by gender and consistently defined for the same age group could only be obtained starting in 2006. 


\section{Table 3: Determinants of Math Attainment}

\begin{tabular}{lcc|cc|ccc} 
& \multicolumn{3}{c}{ Dependent variable: Proportion who can solve division problem } \\
\cline { 2 - 7 } Independent variables: & \multicolumn{3}{c}{ All } & $(1)$ & $(2)$ & $(3)$ & \multicolumn{3}{c}{ Girls } \\
& -0.3226 & 0.2452 & -0.0465 & 0.1105 & -0.1851 & 0.1568 \\
& $(0.274)$ & $(0.258)$ & $(0.177)$ & $(0.136)$ & $(0.196)$ & $(0.143)$ \\
Pupil-teacher ratio & 0.1534 & 0.0919 & 0.0258 & 0.0389 & 0.0071 & 0.0645 \\
Student-classroom ratio & $(0.118)$ & $(0.151)$ & $(0.069)$ & $(0.141)$ & $(0.065)$ & $(0.160)$ \\
& 0.3651 & -0.0876 & 0.3478 & -0.0790 & $0.4176 *$ & -0.0706 \\
\% Schools with drinking water facility & $(0.222)$ & $(0.149)$ & $(0.220)$ & $(0.141)$ & $(0.202)$ & $(0.148)$ \\
\% Schools with girls' toilet & 0.0305 & 0.0818 & -0.0146 & 0.0371 & -0.0128 & 0.0681 \\
& $(0.096)$ & $(0.097)$ & $(0.093)$ & $(0.093)$ & $(0.098)$ & $(0.083)$ \\
\% Classrooms in good condition & -8.4640 & -7.4306 & -0.0721 & -0.0801 & -0.0968 & -0.0242 \\
& $(12.692)$ & $(10.113)$ & $(0.128)$ & $(0.115)$ & $(0.127)$ & $(0.120)$ \\
Constant & 12.3868 & 27.7266 & 15.0396 & $45.0482 * *$ & 14.5608 & $36.2175 *$ \\
& $(18.714)$ & $(16.646)$ & $(19.293)$ & $(19.071)$ & $(17.720)$ & $(20.943)$ \\
\hline Year and state fixed effects & No & Yes & No & Yes & No & Yes \\
Adj. R-squared & 0.146 & 0.778 & 0.100 & 0.806 & 0.193 & 0.835 \\
No. of observations & 119 & 119 & 99 & 99 & 99 & 99
\end{tabular}

Note: Standard errors were clustered at the state level and shown above in parentheses. Significance indicated at the following confidence levels: * 90 percent, ** 95 percent, *** 99 percent. See other notes in Table 1. The number of observations is smaller in columns 3-6 because ASER data that is disaggregated by gender and consistently defined for the same age group could only be obtained starting in 2006 . 


\section{Table 4: Determinants of Out of School Rate}

\begin{tabular}{lcc|cc|cc} 
& \multicolumn{9}{c}{ Dependent variable: Out of school rate } \\
\cline { 2 - 7 } Independent variables: & \multicolumn{2}{c}{ All } & \multicolumn{2}{c}{ Boys } & \multicolumn{2}{c}{ Girls } \\
\hline Pupil-teacher ratio & $0.2316 * * *$ & 0.1443 & $0.1493 *$ & $-0.0976 * *$ & $0.1877 *$ & -0.0848 \\
& $(0.049)$ & $(0.089)$ & $(0.073)$ & $(0.037)$ & $(0.091)$ & $(0.051)$ \\
Student-classroom ratio & $-0.0742 * *$ & $-0.1299 * *$ & -0.0443 & $-0.1133 * * *$ & -0.0572 & $-0.1040 * *$ \\
& $(0.030)$ & $(0.052)$ & $(0.038)$ & $(0.034)$ & $(0.060)$ & $(0.048)$ \\
\% Schools with drinking water facility & $-0.0902 * * *$ & -0.0005 & $-0.0941 * *$ & 0.0308 & $-0.1145 *$ & 0.0390 \\
& $(0.029)$ & $(0.033)$ & $(0.037)$ & $(0.037)$ & $(0.062)$ & $(0.048)$ \\
\% Schools with girls' toilet & -0.0124 & $-0.0366 * *$ & -0.0099 & $-0.0522 * * *$ & -0.0081 & $-0.0633 * * *$ \\
& $(0.014)$ & $(0.016)$ & $(0.022)$ & $(0.014)$ & $(0.030)$ & $(0.017)$ \\
\% Classrooms in good condition & $-4.3589 *$ & $-6.9657 * *$ & $-0.0649 *$ & $-0.1259 * * *$ & -0.0124 & -0.1104 \\
& $(2.415)$ & $(2.782)$ & $(0.032)$ & $(0.030)$ & $(0.045)$ & $(0.048)$ \\
Constant & $9.9488 * * *$ & $11.6671 * * *$ & $14.5661 * * *$ & $21.7187 * * *$ & $12.6385 * *$ & $21.3959 * * *$ \\
& $(2.719)$ & $(3.302)$ & $(2.634)$ & $(3.523)$ & $(5.186)$ & $(4.952)$ \\
\hline Year and state fixed effects & No & Yes & No & Yes & No & Yes \\
Adj. R-squared & 0.557 & 0.806 & 0.453 & 0.846 & 0.269 & 0.833 \\
No. of observations & 119 & 119 & 99 & 99 & 99 & 99
\end{tabular}

Note: Standard errors were clustered at the state level and shown above in parentheses.

Significance indicated at the following confidence levels: * 90 percent, ** 95 percent, *** 99 percent. See other notes in Table 1. The number of observations is smaller in columns 3-6 because ASER data that is disaggregated by gender and consistently defined for the same age group could only be obtained starting in 2006. 


\section{Appendix: Recent Policy Initiatives by the Government of Bihar}

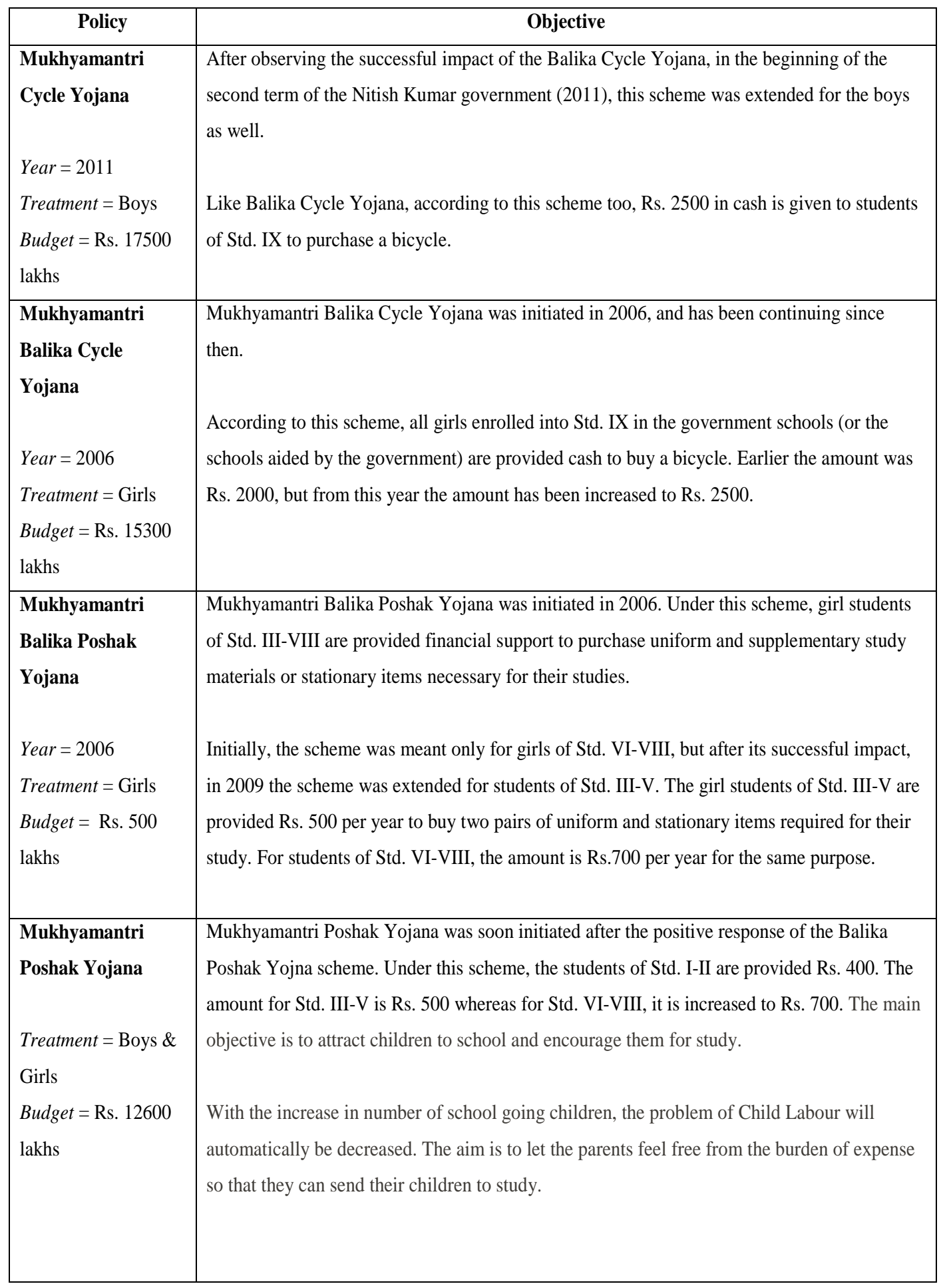




\begin{tabular}{|c|c|}
\hline $\begin{array}{l}\text { Mukhyamantri } \\
\text { Balika Protsahan } \\
\text { Yojana }\end{array}$ & $\begin{array}{l}\text { According to this scheme, all girls who have passed the matriculation examination with } 1^{\text {st }} \\
\text { Division are rewarded with a sum of Rs.10,000/- so that they can afford pursuing further } \\
\text { studies. }\end{array}$ \\
\hline $\begin{array}{l}\text { Treatment = Girls } \\
\text { Budget = Rs. } 5400 \\
\text { lakhs }\end{array}$ & $\begin{array}{l}\text { As there is not proper number of }+2 \text { schools and also as most of the population lies below } \\
\text { average profile, it is still not feasible for girls to opt higher studies. In a way to strengthen \& } \\
\text { stabilize the girls, this scheme provides financial support so that they can initiate for further } \\
\text { study without worrying about family scope and limitations. }\end{array}$ \\
\hline $\begin{array}{l}\text { Mukhyamantri } \\
\text { Paribhraman } \\
\text { Yojana } \\
\text { Year = } 2006 \\
\text { Treatment = Boys \& } \\
\text { Girls } \\
\text { Budget = Rs. } 300 \\
\text { lakhs }\end{array}$ & $\begin{array}{l}\text { The scheme was started in } 2006 \text {. According to this Scheme, each school is provided Rs. } \\
\text { 10000/-to make available educational tour. A group of } 40 \text { students, } 5 \text { from each class are } \\
\text { prepared and taken to some significant place for excursion. } \\
\text { To make the students know about the geographical area, related history and other such facts } \\
\text { that realize them about the state of affairs about their surroundings. The scheme also let them } \\
\text { learn team spirit and work as a group. }\end{array}$ \\
\hline $\begin{array}{l}\text { Text Book } \\
\text { Distribution } \\
\text { Scheme } \\
\text { Treatment = Boys \& } \\
\text { Girls } \\
\text { Budget = Rs. } 5 \text { lakhs }\end{array}$ & $\begin{array}{l}\text { The scheme is concerned with providing free text books to all students from Std. I-VIII. } \\
\text { Earlier till 2008, the scheme was only for 'Focus Group' i.e. for girls and students of SC/ST } \\
\text { category. After that, the scheme was extended for the minority and EBC (Extreme Backward } \\
\text { Class) group. As the scheme turned out successful, it was further extended for all students. } \\
\text { Each Student is provided with a complete set of books. So the number of books' sets prepared } \\
\text { by the Corporation is equal to total number of students. For this year, the number of books' set } \\
\text { is } 19048695 \text {. The Corporation is presently working on for session 2011-12. Total number of } \\
\text { books for this session is } 10 \text { crores } 17 \text { lakhs } 80 \text { thousands and } 297 \text {. }\end{array}$ \\
\hline
\end{tabular}




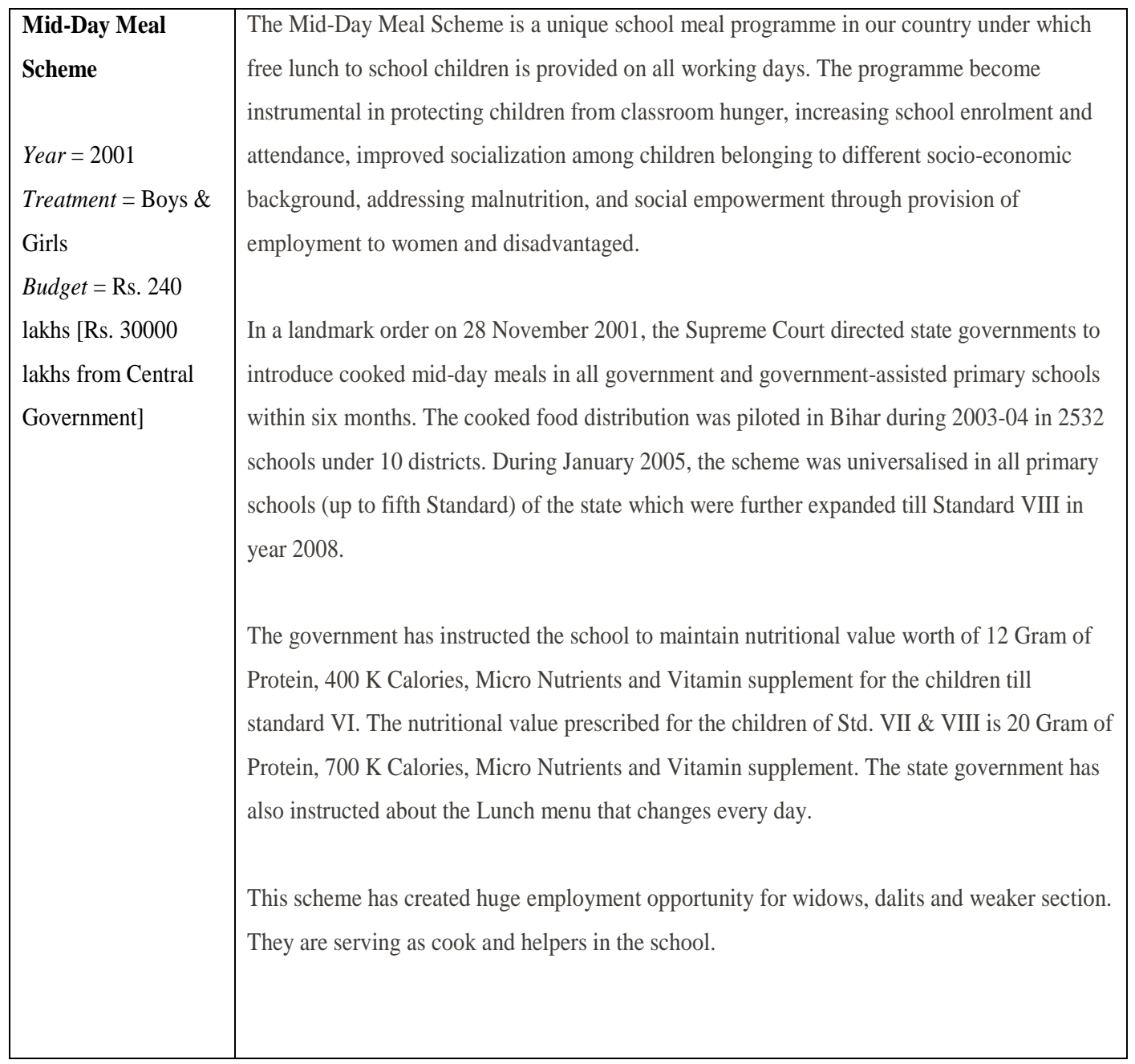

